\title{
II INTERNATIONAL SYMPOSIUM
}

of Medicinal Chemistry and Regenerative Medicine

\section{ITERNATIONAL SYMPOSIUM}

NOVEMBER 22 ${ }^{\text {NO }} \mathrm{TO}^{2}$ 24 $^{\mathrm{TH}}, 2017$

of Medicinal Chemistry and Regenerative Medicine

NOVEMBER 22 ${ }^{\text {NO }}$ TO 24 $4^{\text {TH }}, 2017$

Araraquara/SP - Brazil

\section{$\triangleright$ BIOPOLYMERS - Abstracts}

The II International Symposium on Medicinal Chemistry and Regenerative Medicine, held from November 22nd to 24th at, this event was directed to undergraduate and graduate students, professionals from the medical pharmaceutical, biotechnology innovation management and entrepreneurs, as well as researchers involved in the areas of Medicinal Chemistry, Regenerative Medicine and Biotechnology.

The event aimed to promote the dissemination of new research and innovations that are at the frontier of knowledge in the area of Regenerative Medicine and Medicinal Chemistry and also to promote interaction with : companies interested in these researches. Thus, as a result of the event, it is hoped to encourage discussion, - sharing of knowledge, articulation of partnerships for new research projects and also generate a spark of ideas : that can be led by future entrepreneurs.

In this second edition, a scientific session was held with the presentation of posters. The abstracts submitted and approved by the scientific committee are below.

\section{Central themes}

- Biopolymers

- Medicinal Chemistry

- Regenerative Medicine

- Innovation Management on Biotechnology 
Luminescent chitosan/sodium tripolyphosphate nanoparticles modified with [Eu(TTA)3(Bpy-si)] complex as new biomarkers
Daiane Umbelina Dagostin'; Marco Antônio Utrera Martines; Rafael Miguel Sábio ${ }^{2 *} ;$ Hernane da Silva Barud²; Sidney José Lima Ribeiro ${ }^{3}$; Adriana Pereira Duarte

(Institute of Chemistry, Campo Grande-MS, Braalt

\section{ARTICLE INFO}

Keywords:

Chitosan/sodium tripolyphosphate

anoparticles

Silylated Europium(III) complex

Luminescent biomarkers
( the exoskeleton of crustae biomass obtained by alkaline deacetylation of chitin, easily found in studied by the pharmaceutical industry as a potential agent for the healing of bones and tissues, in treatments for weight reduction and cholesterol, as antimicrobial agent and suitable matrix for coordination compounds as lanthanides ions aiming applications such as cell markers. In this way, the development of new coordination luminophores non-toxic and stable with good luminescence properties even in small concentrations is still a big challenge. In this work, we described the ionic gelation technique as method to obtain Chitosan/TPP nanoparticles (CS/TPP) modified with luminescent silylated [Eu(TTA)3(Bpy-Si)] complex. Materials and Methods: A nanoparticles were prepared by ionic crosslinking or CS dispersions with TPP aqueous solution of CS in 10mL of acetic acid solution $0.1 \mathrm{M}$ at room temperature and mechanical stirring. $\mathrm{NaOH}$ aqueous solution $1 \mathrm{M}$ was used to increase the $\mathrm{pH}$ up to 4.4. After that, TPP solution (10 mg TPP in $10 \mathrm{~mL}$ of water) was added dropwise to $10 \mathrm{ml}$ of CS dispersion under stirring at room temperature for 1h. Simultaneously, $3 \mathrm{mg}$ of [Eu(TTA)3(Bpy-Si)] complex were dissolved in $3 \mathrm{~mL}$ of water and added dropwise to CS/TPP solution under stirring at room temperature for $1 \mathrm{~h}$. Finally, the CS/TPP@[Eu(TTA)3Bpy-Si] obtained was dialyzed for 48h. Results: The nanohybrid were characterized by FTIR, SS-NMR and FE-SEM techniques that confirm the incorporatio of the [Eu(TTA)3Bpy-Si] showing particles with average size of $84 \mathrm{~nm}$. Luminescent properties were evaluated and the intensity parameters were calculated. These results showed that after luminophor grafting onto nanoparticles there was no signifcant decrease in its luminescent luminescent nanohybrids suspension was evaluated in B16F10 cells strain by epifluorescence microscopy. By excitation at $470 \mathrm{~nm}$, red emission of these nanosystems in the cell nuclei can be observed. Conclusions: Preparation of CS nanoparticles and CS@[Eu(TTA)3Bpy-Si] were successfully performed and confirmed by FTIR, SS-NMR, FE-SEM and luminescent measurements. The complex incorporation into the biomatrix was not affected by the acid $\mathrm{pH}$ of the $\mathrm{CS}$ nanoparticles. The choice of the $\mathrm{CS}$ as biomatrix appearing is a good choice to maintain the lu-

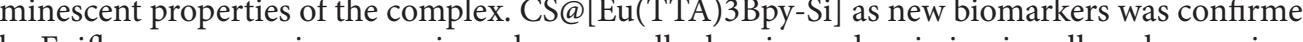
by Epifluorescence microscopy in melanoma cells showing red emission in cell nucleus region.

Financial support: CAPES
Orodispersible films based on gellan gum and cashew gum intended for insulin administration: evaluation of transparency and erosion

Tais de Cássia Ribeiro ${ }^{1, *} ;$ Hernane da Silva Barud ${ }^{1}$; Edson Cavalcanti da Silva Filho²; Andréia Bagliotti Meneguin

\section{ARTICLE INFO}

\section{Keywords:}

Orodispersible films

Cashew gum and gellan gum

ABSTRACT

Introduction: Orodispersible films (FOD) are intended for administration of drugs into the ora cavity. These films can be developed from polymeric materials, such as cashew gum (GC) and gellan gum $(\mathrm{GG})$, since these materials show high mucoadhesive properties and rapid disintegration when placed in the oral environment. The development of these GG / GC-based FODs is in agreement with the need for an alternative route for the treatment of Diabetes melittus, since the subcutaneous route of insulin (INS) administration is an invasive route, causing discomfort, pain and local inflammation, decreasing patient adherence to treatment. The administration of INS through the FOD overcomes the drawbacks related to the enzymatic degradation of INS in the gastrointestinal tract, as well as its low intestinal permeability. Objectives: To analyze the degree oftransparency of GG / GC FODs and its disintegration in artificial saliva. Materials and Methods: Polymeric films were obtained by the solvent casting method from GG: GC dispersion obtained in different proportions $(1: 2,5,1: 5,2,5: 2,5$ and 2,5:1) and labeled as 1G / 2.5C, 1G / 5C , 2.5G / 2.5C and 2.5G / IC, respectively. The FOD transparency measurements were performed on a varian Cary $500 \mathrm{UV}$. were cut and accurately weighed and then placed on the bottom of beakers containing artificia saliva solution at $37^{\circ} \mathrm{C}$ with $50 \mathrm{rpm}$ stirring for 30 minutes. After the immersion time, the film were removed, oven dried at $60^{\circ} \mathrm{C}$ for 48 hours and weighed. Erosion was calculated gravimetrically. Results: The transparency measures in the visible region of the spectrum revealed that the films presented transmittance percentage ranging from 60 to $70 \%$. The spectra showed that films GC did no cor cen disperse, blocking the passege of light. Likewise, films with a lowe GC did not completely disperse, blocking the passage of light. Likewise, films with a lower CO light. In the erosion test performed in simulated saliva solution, the $1 \mathrm{G} / 2.5 \mathrm{C}$ sample presented light. In the erosion test performed in simulated saliva solution, the $1 \mathrm{G} / 2.5 \mathrm{C}$ sample presented

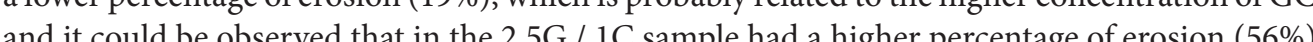
with a lower GC concentration. Conclusion: We conclude that the degree of transparency we FOD is a promising property since it is a tron cornt solution and favors an application of the material in the biomedical area. According to erosion data the $2.5 \mathrm{G} / 1 \mathrm{C}$ sample was more

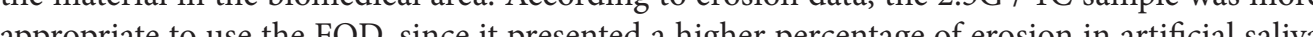
solution. Erosion testing is extremely important, since erosion also of incorporated drug, for mucoadhesive systems may be a good strategy for increasing permeation. 


\section{International Journal of Advances in Medical Biotechnology}

Journal homepage: http: www.journalamb.com/index.php/jamb

Antimicrobial biomaterial based on polysaccharide

Fábio Ribeiro'; Ana Anastacio ${ }^{1}$; Taiane Maria de Oliveira ${ }^{1} ;$ Alyne Rodrigues de Araujo ${ }^{1}$; Patrick Veras Quelemes ${ }^{1} ;$ Jose Roberto de Souza de Almeida Leite². Durcilene A. Silva'

'University Federal of Piauri' 2 University of Brasilia,-Brazi

ARTICLE INFO

\section{Keywords:}

Biomembranes

Anti-Staphylococcal Activity

BSTRACT

Introduction: The manufacture and use of biodegradable biomembranes from polymer with incorporation of bioactive drugs or molecules has aroused industry interest for the manufacture of dressings used in wounds and sutures. Among these polymers, polysaccharides like gums stand water-soluble and need to have improved physical properties for such asplication With the current challenge of developing new biodegradable matrices for drug incorporation this work has the objective of making membrane for application as an antimicrobial dressing. Materials and Methods: Three types of modified polymer were developed and characterized by FTIR, elemental analyses. Results: Characterization by FTIR showed a presence of bands between 1560 and $1490 \mathrm{~cm}^{-1}$, characteristics of amines functional groups. In addition, the modified gum exhibits anti-staphylococcal activity.

Financial support: FAPESP-PPSUS
International Journal of Advances in Medical Biotechnology

Journal homepage: http: www.journalamb.com/index.php/jamb

Assessment of mutagenicity of polymer films of Allium Cepa L. With application for food packaging

Mariana Rodrigues Barreto ${ }^{1, *}$; Nathália Ferreira Fregonezi1; Clóvis Ribeiro ${ }^{2}$

Diógenes Dias'; Hernane Barud', Flávia Aparecida Resende

University of Araraquara - UNIARA, Araraquara-SP, Brazil. 3nstitute of Chemistry - São Paulo State University - UNESP, Araraquara-SP, Brazil.

\section{ARTICLE INFO}

Keywords:

Food packaging

Mutagenicity

Ames test

ABSTRACT

Introduction: Nowadays, most of the food packaging systems are based on petroleum-derived synthetic plastics, whose production has increased exponentially over the past two decades Nevertheless, he utilzation of these materials involves a serious environmental problem and high recycling costs. In order to deal with this issue, current research focuses on the development of biodegradable materials from renewable sources. So, polymer films of Allium cepa $\mathrm{L}$. are being produced for this purpose. However, because it touches the food and chemicals can migrate into the food, their safety should be regulated. Objectives: Thus, the aim of the present study was to determine the mutagenic effects of the onion-based washed and not washed films (Allium cepa L.) with application for food packaging. Materials and Methods: The films were produced in BioSmart Nanotechnology Company and gently donated by Dr. Diogenes dos Santos Dias. Mutagenic activity was evaluated by the Salmonella/microsome assay (Ames test), using the Salmonella typhmm wim tester strans TA98 and TA97a (detect frameshift mutations), TA100 (detect base-parr-substitution mutations) and TA102 (normally used to detect mutagens that cause oxidative damage and base-pair-substitution mutations), with ( + S9) and without (9) metabolization, by the preincubation method. Results: The results showed only signs of mutagenicity of the not washed films with the largest mutagenic indexes of 1.9 . The washed films did not induce an increase in the number of revertant colonies relative to the negative control indicating absence of mutagenic activity, under the conditions used. Conclusion: The detection and and carcinogens. These results contribute to valuable data on the safe use these materials for commercial purposes.

Financial support: Uniara and Prosup (Brazil) 


\section{International Journal of Advances in Medical Biotechnology}

Journal homepage: http: www.journalamb.com/index.php/jamb

Citotoxicity and mutagenicity studies of tempo-oxidized cellulose nanofibers

Amanda de Lima Pizi Cândido ${ }^{1 ;}$; Nathália Ferreira Fregonezi1; Mariana Rodrigues Barreto'; Eliane Trovatti'; Flavia Aparecida Resende

'University of Araraquara - UNIARA, Araraquara-SP, Brazil

\section{ARTICLE INFO}

\section{Keywords:}

Biomaterials

Cellulose

Nanofibrillar cellulose

Mutagenicity

Cytotoxicity

ABSTRACT

Atroduction: Nanocellulose is described as a product or extract of a native cellulose composing material with a nanomeric structure. Despite being considered the most attractive renewable material for advanced applications due to its unique physical and mechanical properties, little is known about the mutagenic potential and cystoxic effects of nanoscale cellulose. Thus, the evaluation of mutagenicity and cytotoxicity in substances with promising applicability within tissue engineering, such as cellulose, is necessary owing to the fact that further tissue damages can be avoided. Objectives: Therefore, the objective of this study was to evaluate the mutagenic activity of TEMPO-oxidized cellulose nanofibers ( $\mathrm{TOCNF}$ ) by the Ames test, a widely used assay to detect mutations at the gene level, and its cytotoxic potential by the MTT assay. Materials and Methods ToCN was produced in Ulian Trovatti, PhD. In this study, the Ames test was performed with changed strains of Salmonella yphimurium (TA98, TA97a, TA100 and TA102) and for the MTT assay were employed a norma (Ache According with the results obtained in this report, the modified cellulose did not induce any statistially signicant diference neither in the number or revertant colonies or s. typhimurium con the cen wa ides reliable data to support future clinical researches. Hower further toxicologit eeded to ensure its safe use.

Financial support: Uniara and Fapesp (Brazil)
International Journal of Advances in Medical Biotechnology

Journal homepage: http: www.journalamb.com/index.php/jamb

Rheological behavior of sodium alginate hydrogel containing bacterial cellulose

Fernanda Mansano Carbinatto ${ }^{1}, ;$ Silvia Cestari ${ }^{2}$; Sandra Andrea Cruz $^{3} ;$ Hernane da Silva Barud ${ }^{1}$

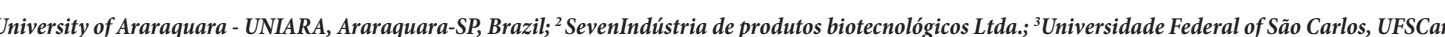

\section{ARTICLE INFO}

Keywords:

Bacterial cellulose

Hydrogel

Sodium alginate

Rheology

ABSTRACT

Antroduction and objectives: Hydrogels are three-dimensional hydrophilic networks with capable of absorbing large quantities of water or biological fluids. Hydrogels are biodegradable and biocompatible with of organic/inorganic products. Various polymeric materials are used to form hydrogels howerer, the of polysaccharides, such as the use of alginate hydrogels has been increased due to the biocompatibility biodegradability, immunogenicity, and non-toxicity properties. The possibility of incorporation of bacterial cellulose (BC) nanofibers into alginate hydrogels is very interesting in several areas of knowledge, such as medicine, since the structure of $\mathrm{BC}$ is a viable matrix to assist the treatment of dermal lesions and it has been used as a temporary substitute for skin, burns, ulcers, grafts, as a wound cover and to aid in dermal abrasions. The aim of this work was to develop alginate hydrogels containing BC nanofibers and also investigate the rheological behavior of the developed hydrogels which inpact when applied to the skin. Matemats and Methods: Hydrogels of sodium alginate with calcium were developed using diferent polymenc of BC. Rheological behavior was evaluated with parallel plate rheometer (Anton Paar) was used to measure the complex viscosity $\left(\eta^{*}\right)$ the storage modulus $\left(G^{\prime}\right)$ and the loss modulus ( $\left.G^{\prime \prime}\right)$ as a function of frequencyTests used $25 \mathrm{~mm}$ diameter plates at a temperature of $32^{\circ} \mathrm{C}$. The range of frequencies used was 0.01 to 500 $\mathrm{rad} / \mathrm{s}^{1}$ at $2 \%$ strain, which proved to be in the linear viscoelastic range according to a prior amplitude sweep test. The gap between plates was $1.00 \mathrm{~mm}$. Flow curve was also analyzed with shear rate range from 0 to 100Pa/s for the ascent ramp for 120 seconds and from 100 to $0 \mathrm{~Pa} / \mathrm{s}$ for the descent ramp for 120 second. Results and Conclusions: The resulss obtained in this study demonstrate that alginate hydrogels with $\mathrm{CB}$ presented a among the components indicating a stable structure which makes it difficult to separate the constituents of the formulation besides being indicative of greater stability of these hydrogels.

Financial support: SevenIndústria de produtos biotecnológicos Ltda. 
Cytotoxicity, antimicrobial activity and morphology of bacterial cellulose with chitosanfilm loaded with ciprofloxacin

Gabriel L. Martins ${ }^{1 *} ;$ Maximiliano L.Cacicedo ${ }^{2}$; German A. Islan'; Renata A. de Carvalho'; André C. Amaral'; Creusa S. T. Amaral ${ }^{1}$ Guillermo R. Castro²; Hernane S, Barud'; Guilherme Pacheco

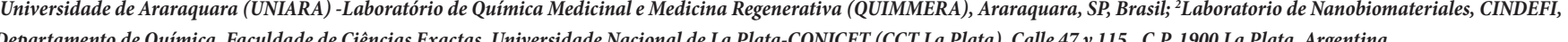

ARTICLE INFO

\section{Keywords:}

Bacterial cellulose

Chitosan

Wound healing Introduction and objectives: Treatment of skin lesions is a great clinical importance, justifying the high investments in new products that reduce the time of healing and increase the patient comfort. As a result, different products and patches are market, however, most are imported and make the treatment expensive. In this context, biopolymers gain prominence in the industry due to its efficient, abundant and low cost, such as bacterial cellulose and chitosan. In the present work, the objective was to analyze the cytotoxicity, antimicrobial property and morphology of the film produced by bacterial cellulose and chitosan associated with ciprofloxacin.

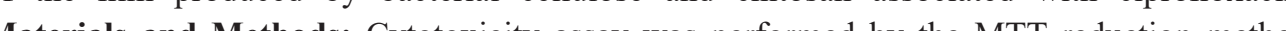
(\{3- (4, 5-dimethylthiazol-2-yl) -2,5-diphenyltetrazolium bromide), which allows measuring the amount of viable cells based on the principle reduction of MTT salt by mitochondrial enzymes to formazan (ISO 10993-5), in human fibroblast cells GM07492.Inhibition halos against Pseudomonas aeruginosa and Staphylococcus aureus were determined by using modified disk diffusion method according to international clinical standards (CLSI/NCCLS), replacing disk for empty and ciprofloxacin loaded BC/chitosan films in the agar plate surface (Mueller Hinto agar) and inoculated with bacteria ( $0.5 \mathrm{McF}$ arland scale). SEM experiments were carried out using samples previously coated with evaporated carbon. The images were obtained using the JEOL T-300 microscope operating at $2 \mathrm{kV}$. Results: Cytotoxicity assay demonstrated that the negative control group and $\mathrm{CB}$ determined the same pattern of cell viability, evidencing the absence of toxicity from the extract of the $\mathrm{CB}$ membranes analyzed. Ciprofloxacin loaded BC/chitosan samples exhibited a significant but slight decrease in the metabolic activity of cells. In contrast, it does not characterize a cytotoxic influence, considering the percentage of viability exhibited in the analyzes (ereter than 80\%) Antimicrobit activity tests, the ciprofloxacin loded BC/ a tested, in evidence against Pseudomonas aeruginosa that showed higher activity than against Staphylococcus aureus. The results also showed the antimicrobial activity of chitosan against Pseudomonas aeruginosa, evidenced in the small inhibition halo formed when inoculated the BC/chitosan film, without ciprofloxacin. Analysis of SEM images revealed surface and transversal section morphology of films. The surface was homogeneous and characteristic of chitosan. From the transversal sectional images, was observed the chitosan in the center of film immersed in the bacterial cellulose membrane, and at the extremities of the film. Conclusions: Generally, the film did not prove to be toxic, in addition, it presented antimicrobial activity against the tested microorganisms and had its morphological structure characterized. Presented research work will open new prospect for the development of composites that could be used as wound dressing and them potential applications in tissue engineering.
Journal homepage: http: www.journalamb.com/index.php/jamb

Effect of palygorskite clay on the release properties of metronidazole from bacterial cellulose membranes

Andréia Bagliotti Meneguin ${ }^{1,2, *}$; Guilherme Pacheco ${ }^{1}$; Hernane S. Barud ${ }^{1}$; Edson Cavalcanti da Silva Filho

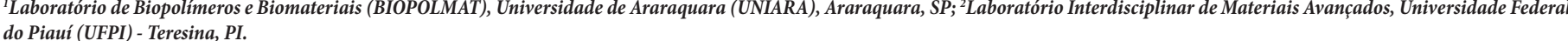

\section{ARTICLE INFO}

Keywords:

Palygorskite

Metronidazole

Bacterial Cellulose

ABSTRACT

ntroduction and objectives: Bacterial cellulose (BC) is synthesized by different species of bacteria and shows many advantages in relation to plant cellulose. In pharmaceutical field, $B C$ has

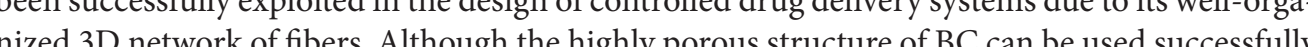
for the network of fibers. Although the highly porous structure or BC can be used successtully for the preparation of new nanocomposites, it promotes the fast release of the drug in a short

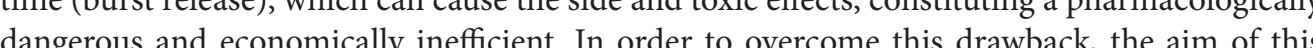
dangerous and economically infe the of silanol groups on the external surface and high internal area as a strategy for the effective ( with 2:1 crystalline structure. Materials a Me hods: PAL was dispersed in an a solution $(10 \mathrm{mg} / \mathrm{mL}$ ) in different proportions $(1: 1,7: 1$ and 15:1) under magntic stiring at 750 $\mathrm{cm}, 30^{\circ} \mathrm{C}$ for $72 \mathrm{~h}$. BC membranes synthesized by Komagataeibacter rhaeticus in Hestrin and Schre tion. In vitro MTZ release was carried out using USP type V dissolution apparatus (paddle over disk) in a Hanson Research (New Hanson SR-8 Plus) dissolution station, using phosphate buffer (0.1M; $\mathrm{pH} 60$ ) according to sink conditions at $37 \pm 0.5^{\circ} \mathrm{C}$ under $50 \mathrm{rpm}$ rotation Release profiles showed that MTZ directly incorporated in BC $(0 \%$ PAL ) depicted a burst effect of release $(62 \%)$ in the first $30 \mathrm{~min}$, which is probably attributed to the high porosty of $\mathrm{BC}$. well as to the drug molecules adsorbed on the membrane surface, allowing their free diffusion. After 180 min of test, $82 \%$ of MTZ was released. Samples containing 1:1 and 7:1 PAL:MTZ were not effective in the release control, showing a release profile similar to that of the control sample. However, the sample prepared with the highest ratio of PAL (15:1) allowed the prolongation of release rates, so that after $180 \mathrm{~min}$ of test, only $60 \% \mathrm{MTZ}$ was released. According to the kinetic study, the mathematical model that best correlated was that of Weibull with parameter $b>1$, re vealing that the MTZ release was governed by a complex mechanism, involving diffusion, swelling and erosion. Conclusion: The set of results indicate that the strategy proposed to overcome the fast release of drugs from $B C$ matrices was very efficient, suggesting its use as an importan technological platform for controlled release.

Financial support: $\mathrm{PNPD} / \mathrm{CAPES}$ 


\section{International Journal of Advances in Medical Biotechnology}

Journal homepage: http: www.journalamb.com/index.phpljamb

Hybrid bacterial cellulose - pectin films for transdermal delivery of bioactive molecules

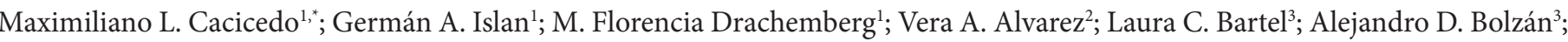
Guillermo R. Castro'

"Laboratorio de Nanobiomateriales, CINDEFI, Departamento de Quimica, Facultad de Ciencias Exactas, Universidad Nacional de La Plata-CONICET (CCT La Plata), Calle 47 y 155. C.P. B 1900ASH

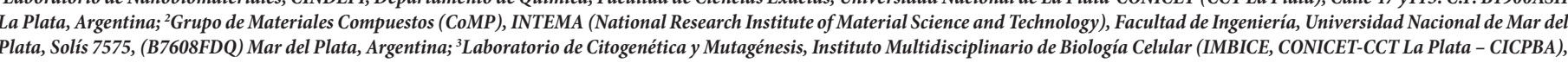
C.C. 403, 1900 La Plata, Buenos Aires, Argentina.

\section{ARTICLE INFO}

\section{Keywords:}

Bacterial cellulose

Transdermal delivery

Polymeric film

Levofloxacin

ABSTRACT

Introduction and objectives: Novel biopolymeric films based on bacterial cellulose (BC) modified with high methoxylated pectin (HMP) were developed for transdermal drug deliver Materials and Methods. The ability of fllms to incorporate an antibiotic, levolloxacin (Levo), was analyzed. Incorporation efficiencies (EE) were determined using films with different proportions of and deep structural changes in $\mathrm{BC}$ matrix. Besides, $\mathrm{HMP}$ presence decreased water loss in the $\mathrm{BC}$ film from 93\% to 75\% after $90 \mathrm{~min}$. Additionally film incorporation capacity of macromolecules using Human Serum Albumin (HSA) as a model protein, was studied. HMP presence enhanced in more than 3.5 times the EE of HSA and no pH dependence was observed. Release kinetic of both molecules showed hyperbolic profiles with sustained release. On independent experiments, HMP presence generated around 50\% decrease on both macromolecules release tes. Additionally, the incorportion of HSA into BC-HMP matrix exhibitied a modulation on Levo release profile. The antimicrobial activity of Levo released from the BC-HMP-HSA film was confirmed using Staphylococcus aureus. In-vitro studies revealed no apparent cytotoxicity work the versatility of bacterial cellulose material was tested by in situ modification, on this additive biopoolymer. The hybrid material exhibited proper characteristic for its application as a transdermal graft with antibiotic properties.

Financial support: The present work was supported by Consejo Nacional de Investigaciones Cientificas y Tecnicas (CONICET, PIP 0498), Universidad Nacional de La Plata (Grant X545, 159) and Agencia Nacional de Pronoción Clentifica y Técnica (ANPCyT, PICT2011-2116) of Argentina.lC Bate had a riotun Cellowship of the Alexander vo Also, we want to thank CPKelco (Buenos Aires, Argentina) for the pectin samples.

\section{International Journal of Advances in Medical Biotechnology}

Journal homepage: http: www.journalamb.com/index.php/jamb

Biocomposites based on tpp crosslinked chitosan / bacterial cellulose as a potential strategy for Ciprofloxacin release

Baru

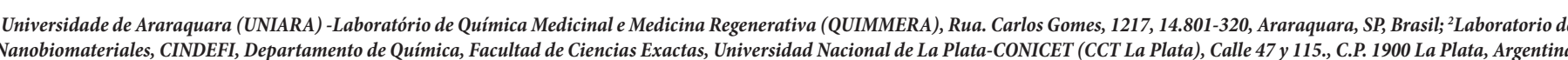

ARTICLE INFO

\section{Keywords:}

Acterial cellulose

Chitosan

Ciprofloxacin

BSTRAC

Introduction and Objectives: Bacterial cellulose $(\mathrm{BC})$ presents high crystallinity fibers of nanometric size gives it a greater water hold capacity and not contain lignin, pectin and reas. Chitosan is a pucture. The polymer has been studied, produced and applied in severa of polymeric $(1 \rightarrow 4)$-linked 2 -amino-2-deoxy- $\beta$-D-glucopyranose units. Because of the biocompatibility, non-toxicity, biodegradability, and intrinsic antibacterial properties, chitosan is considered as a versatile material with potential biomedical applications. Therefore, the aim and chitosan loaded with ciprofloxacin and to evaluate the antimicrobial capacity and (TPP) vitro release study of ciprofloxacin. Materials and Methods: The commercial kitLIVE / DEAD BacLight ${ }^{\circ}$ were used for microbiological assays and the bacteria Pseudomonas aeruginosa and Staphylococcus. aureus were incubated at 24 hours to allow biofilm formation. Subsequently, biofilms were completely covered with empty and ciprofloxacin loaded BC/Chitosan films for 10 30 and $60 \mathrm{~min}$. Controls with untreated bacteria (Live) and $\mathrm{HClO}$ treated biofilm (Dead) were performed. Then, were observed in a Leica DM 2500 epifluorescence microscope (Germany) equipped with UV filters $(495-505 \mathrm{~nm}$ ) at $400 \mathrm{X}$ to deternine the viability of the bacteria. Ciprofloxacin release was evaluated in phosphate buffer $(10.0 \mathrm{mM}$ pH 5,8). Briefly, one film $(10 \mathrm{~mm}$ ) was incubated in $20 \mathrm{~mL}$ buffer at 37 . Samples were taken at different times, an Pseudomonas aeruginos and Staphylococcus, aureus, a reduction in the bacterial population was observed after 30 and 60 minutes of contact with the bacteria, increasing as time passed. The release profile of ciprofloxacin showed a gradual release in $15 \mathrm{~min}$ (37\%) and $25 \mathrm{~min}(52 \%)$ until a burst in $50 \mathrm{~min}(80 \%)$ and follow constant. After this quickly release, significant percentages of the amounts of drug released up to $300 \mathrm{~min}$ were not observed, suggesting a prolongation of the release, which could be exploited for pathologies in which an initial loading dose is required followed by maintenance of the dose of the antibiotic. Conchusions: The rapid release verified by the study suggests that the system provides an enough drug for its effectiveness, corroborating

Financial support: CAPES 
Synthesis, pressing and characterization of bacterial cellulose produced by Komagataeibacter Rhaeticus Gabriela A. Marcondes ${ }^{1 *}$; Jorge A. Achcar ${ }^{1}$; Andreia B. Meneguin'; Hernane Barud ${ }^{1}$; Guilherme Pacheco

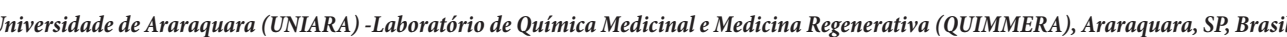

\section{ARTICLE INFO}

Keywords:

Hydraulic Press

Central Composite Design

Introduction and Objectives: Cellulose is a homopolymer of D-glucopyranose residues linked by $\beta-(1 \rightarrow 4)$ glycosidic linkages and is metabolized in plants, animals and secreted by specific enera of bacteria. Bacterial cellulose (BC), presents high crystallinity, fibers of nanometric size which gives it a greater water hold capacity and differs from vegetal cellulose as it does not contain lignin, pectin and hemicellulose in its structure. The polymer has been studied, produced and applied in several areas. However, about BC produced by Komagataeibacter rhaeticus, there are few reports in the literature regarding its characteristics, either after a process of membrane pressing. Therefore, the objective of this work is the characterization of the morphological structure and mechanical and thermal characteristics of the $\mathrm{BC}$ after pressing process of pressed by a hydraulic press, evaluating the variables: pressing time of 10,20 and 30 seconds and forces of 1,2 and 3 tons, according to central composite design to verify the influence of the press in parameter morphological, mechanical and thermal.SEM experiments were carried out using in parameter morphological, mechanical and tarormal.seM experiments were carried out using
samples previously coated with evaporated carbon. The images were obtained using the JEOL T-300 microscope operating at $2 \mathrm{kV}$. Mechanical properties of membranes were evaluated using texture analyzer TA-XT2 (Stable Micro Systems). Force displacement curves were recorded until the film rupture and used to determine the puncture strength (Ps), elongation at break $(\mathrm{Eb})$, perforation energy (Ep). Thermogravimetric analyses were performed using an SDT Q600 (TA Instruments, USA), at $20^{\circ} \mathrm{C} / \mathrm{min}$ under nitrogen atmosphere $(30 \mathrm{~mL} / \mathrm{min})$. Results: SEM images shows that the pressed samples presented more compacted fibers, and tended to align in the same direction as the increase of the force and time of pressing. It was also observed a lower porosity when compared to $\mathrm{CB}$ without treatment. In the mechanical analysis, $\mathrm{BC}$ with treatment presented a progressive puncture strength, according to a gradual increase of force and pressing time, however, this value was lower with $\mathrm{BC}$ without treatment. In the elongation at break, $\mathrm{BC}$ without treatment presented lower value when compared to the membranes with treatment that presented greater elongation. All samples showed a similar thermal behavior, the curves obtained displayed two mass losses. The first one, a small mass loss related to loss of surface water $(\sim 3.7-$ 5.5). The second mass loss event was attributed to the sample decomposition process of cellulose ( $74-84 \%)$. Conclusions: The data obtained so far show that the use of the BC treatment pres can change its morphological structure beyond the mechanical and thermal properties.

Financial support: CAPES
Journal homepage: http: www.journalamb.com/index.php/jamb

Babassu Mesocarp (Orbignya phalerata) Modified With Phthalic Anhydride For Applications In Electrochemical Sensors Of 5-Fluorouracil Chemotherapeutic

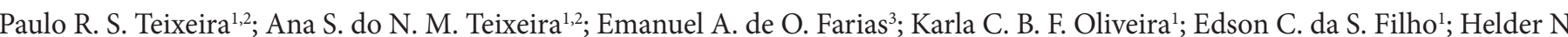

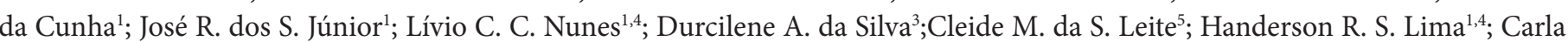
Eiras $^{1,3}$

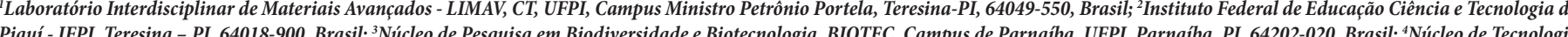

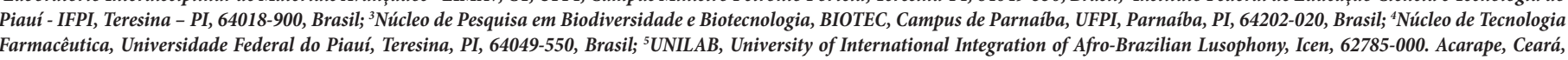

\section{ARTICLE INFO}

\section{Keywords:}

Babassu Mesocarp

Gold Electrode

Sensor

5-Fluorouracil

Electrochemistry

ABSTRACT

Introduction and Objectives: 5-Fluorouracil (5-FU) is a broad-spectrum drug used in the treatment of neoplasms such as glioblastoma and several other cancers, including head and neck cancer, gastrointestinal tract cancer, and breast cancer. On the other hand, there is no knowledge of a level of exposure to 5-FU that is considered safe, for example, for those who are not in chemotherapy treatment. The occupational exposure to $5-\mathrm{FU}$, even for a short time as is the case of healthcare professionals who administer these drugs, can cause adverse effects such as skin rashes, nausea, hair loss, allergic reactions, damage in DNA, etc. Thus, it is very important to develop low-cost sensors capable of detecting 5-FU in different samples and at low concentrations. In this perspective, the objective of this study was the development of electrochemical sensors for detection of 5-FU, from the use of a polymer extracted from babass mesocarp (BM), which was chemically modified with phthalic anhydride (BMPA) to improve its solubility and electrochemical properties. Material and Methods: The reaction for BMPA synthesis was based on literature. A flexible gold electrode (FEAu) was constructed for this study, in which the cost of the electrode was estimated at approximately 0.027 US dollars. The FEAu was modified with a micro droplet $(10 \mu \mathrm{L})$ of a solution containing BM or BMPA at $1.0 \mathrm{mg} / \mathrm{L}$. The electrochemical assays were performed in a conventional electrochemical cell, using $\mathrm{FEAu/BMPA}$ as working electrode. Results: The modification in babassu mesocarp with phthalic anhydride was confirmed by FIIR, XRD, TG/DTG, Zeta Potential, and SEM analysis. The modification caused a very positive effect on the electrochemical behavior of the polymer, since the BMPA showed a more reversible redox process and with greater electrochenical stability in relation to BM. The current of oxidation process of 5-FU had an increase of $276 \%$ when FEAu/BMPA electrode was used. Also was observed a displacement in the oxidation potentials of BMPA in presence of $5-\mathrm{FU}$, suggesting strong interaction between them. After construction ofa calibration plot for 5-FU using FEAu/BMPA electrode, the analytical sensitivity and the limit of detection for 5 -FU were estimated at $8.8 \mu \mathrm{A} / \mu \mathrm{mol} / \mathrm{L}$ and $3.4 \times 10^{-2} \mu \mathrm{mol} / \mathrm{L}$, respectively. Conclusions: Electrochemical sensors developed from babassu mesocarp may be an economically viable alternative for monitoring of the 5-Fu antineoplastic, since in addition to being sensitive to th drug they are constructed of a natural polymer, renewable and widely abundant in nature. 
Journal homepage: http: www.journalamb.com/index.php/jamb

Development of sensor device based on purified palygorskite associated with antimicrobial peptide DRS 01

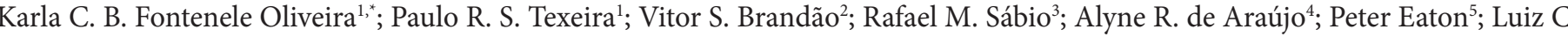
Bertolino'; Marcelo P. Bemquerer ; Hernane da S. Barud ${ }^{3}$; José R. de S. de A. Leite'; Carla Eiras ${ }^{1,4}$

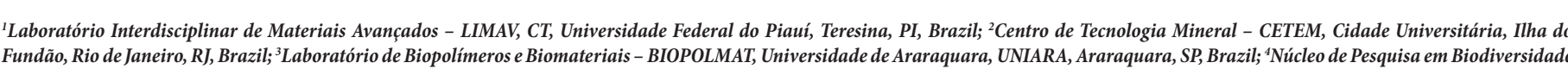

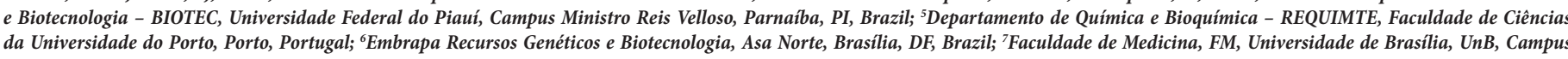

ARTICLE INFO

\section{Keywords:}

Fibrous Clay minerals

Attapulgite

Pithecopus hypochondriali

Nanostructured Film

Layer-By-Laye

ABSTRACT

Introduction and Objectives: Biomolecules immobilization is a promising approach in development of sensor devices. Antimicrobial peptides (AMPs) are part of the innate immune system of several organisms with firmly established antibiotic potential that can be used as recognition elements for target substances in biosensor devices. Clay minerals are inorganic solids of crystalline structure with morphology and unique physicochemical features, such as adsorptive and thermal properties. In this sense, these inorganic systems have emerging as suitable matrices for anchorage of organic molecules. This work reports the purification, characterization and application of nanocrystals of palygorskite (PAL), a fibrous clay mineral from Guadalupe (state of Piaui), for immobilization of the peptide Dermaseptin 01 (DRS 01) bylayer-by-layer (LbL) technique to develop an electro active film for applications as biosensor device. Materials and Methods: The natural PAL was submitted to physical and chemical purification processes for the entichment of tis adsorptive properties and the concentration of clay-mineral. Structure, chemical composition and morphology of PAL were investigated by X-Ray Diffraction (XRD) Fourier-Transform Infrared spectroscopy (FTRR), X-Ray Fluorescence spectrometry (XRF) fanning Electron Microscopy (SEM) and Transmission Electron Microscope (TEM). Lb (ITO) substrates in dispersions of $1 \mathrm{mg} / \mathrm{mL}$ of PAI and DRS 01 for five minutes. Films were

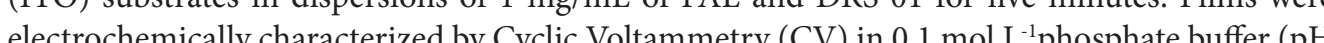
7.25) UV-Visible spectroscopy FTIR attenuated total reflection (FTIR-ATR) and Atomic Force Microscopy (AFM) Results: PAL was purified with enrichment of its properties as conf Force XRD and FTIR techniques with pronounced reduction of quartz peaks. The results for ITO/DRS 01 and ITO/PAL/DRS 01 films showed an oxidation process at $+0.77 \mathrm{~V}$ confirming the DRS 01 maintained its electro active behavior, when together with PAL. The results of $C V$ showed differences in the current density of $1.82 \mathrm{H} \mathrm{cm}^{-2}$ for the film containing unpurifed PAL (ITO/

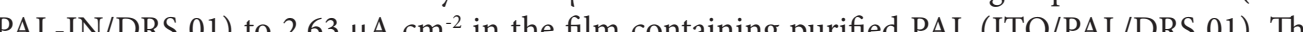
3-bilayer ITO/(PAL/DRS 01) film showed an increase in current density values that was a $460 \mathrm{~A} \mathrm{~cm}^{-2}$ compared to the film with a single bilayer. Conclusions: The purifcrion of chy mineral played an important role in the electrode response. The nanostructured film developed emerges as a low-cost platform, verstile and easy to prepare, even on other substratos for biodetection of pathogens in clinical, exirongent phl pharnaceutical anlysis, as well as other biotechnological applications.
International Journal of Advances in Medical Biotechnology

Journal homepage: http: www.journalamb.com/index.php/jamb

Scaffolds of pla (POLYLACTIC ACID) obtained by additive manufacturing functionalized with calcium polyphosphate coacervate for application in tissue engineering

Ana Beatriz Viale ${ }^{1 *} ;$ Hernane Barud ${ }^{1}$; Douglas Faza Franco ${ }^{2}$; Renata Aquino de Carvalho'; André Capaldo Amaral'; Mônica Rosas da Costa Iemma'; Lorenzo Machado

-

\section{ARTICLE INFO}

Keywords:

Tissue Engineering

PLA

caffolds

BSTRACT

Introduction: Tissue Engineering have been gaining prominence, since it has a wide range of applications. The general purpose is development of biological substitutes for repairing and/ or replacement of damaged tissues. There are three basic elements for tissue engineering: Cell, which is responsible for formation of new tissue; Biocompatible Polymer Matrix, which provides an appropriate environment and support for cell growth; and the Grownh Factors, which are biologically active molecules that stimulate and define the cell differentiation. 3D printed poly-acid lactic scaffolds could be a promising technology for tissue engineering application. In order to improve cell adhesion and proliferation on PLA scaffolds, 3D samples have been modified with polyphosphate coacervate, which is a rich gel-like containing mainly phosphoru and calcium elements. Objectives: The aiming of this work is surface modification of 3D-PLA scaffold using polyphosphate coacervate as coating and modifier agent. Materials and Methods Commercial flaments $5 \mathrm{~mm}$ of height) by UP-3D plus 3D printer. 3D-PLA scaffolds were submerged for $24 \mathrm{~h}$ in polyphosphate coacervate at room temperature. PLA-Coacervate samples were frozen and lyophilized. Results SEM images indicate that the polyphosphate coacervate clusters were within PLA 3D structures. The layer-by-layer scaffold structure was kept intact. EDS data indicates presence of oxygen,

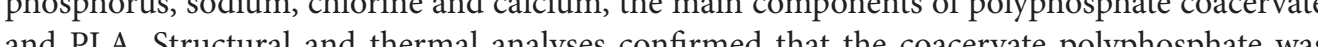
and PLA. Structural and ther nconported in pla scaflds. Conclisios. Cytotosicily and cell adhesion preliminary tes sugest the possibility to use this new scaffold in medical applications. 


\section{International Journal of Advances in Medical Biotechnology}

Filaments for 3d printing based on polymeric blends of poly-hydroxybutyrate / starch for applications in tissue engineering

Igor T. S. Batista ${ }^{1+} ;$ Henrique Finoccio.Precisa ${ }^{2} ;$ Hernane S. Barud $^{1}$

'Wniversity of Araraquara - UNIARA, Araraquara-SP, Brazili' ${ }^{2}$ ffinko Polymers, Säo Carlos-SP, Brazil

ARTICLE INFO

\section{Keywords:}

3D printing

Polymeric blends

Poly-hydroxybutyrate and starch

ABSTRACT

Currently have been growning the interest in biopolymers for the production of biomaterials using 3D printed, since they are biodegradable, biocompatible and non-toxic. Among all natura polymers, poly-hydroxybutyrate (PHB), which is a polymer produced from bacteria Alcaligenes eutrophus, it is a renewable, linear, semi-crystalline resources and belonging to the class of poly-hydroxyalkanoates. The main disadvantage of this biopolymer is the high cost in production and some deficiencies in their properties such as low mechanical resistance and thermal instability. To address these deficiencies is possible the association of PHB with natural additives, such as starch, cellulose and others natural polymers. In this work, polymers blends filaments based on different proportions of $\mathrm{PHB} /$ starch have been prepared using a homemade extruder of single screw. The obtained filaments have been characterized as Scanning Electron Microscopy (SEM), thermogravimetric analysis (TGA), mechanical tests of tensile and impact, and biodegradatio test. The filaments have also been tested using 3D printed fused deposition modeling (FDM) method in order to produce prototypes that can be applied as a biomaterial in tissue engineering.
II INTERNATIONAL SYMPOSIUM

of Medicinal Chemistry and Regenerative Medicine

NOVEMBER 22ND TO 24 ${ }^{\text {TH }}, 2017$

Araraquara/SP - Brazil

\section{DInNovation Management on - Abstracts}


Regulatory process of a bioceramic laboratory by the health surveillance guideliness

André Candido Porto ${ }^{1,2,} ;$ Fábio Trevelin Centanin ${ }^{2,3}$

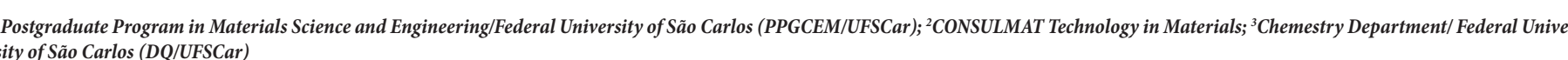
ARTICLE INFO

\section{Keywords:}

Regulatory Guidelines

Health Surveillance

Ceramic Biomaterials

Laboratory Management

ABSTRACT

Introduction: Biomaterials production companies, specially, bone grafts based in bovine bone mineral matrix $(\mathrm{CaP})$, needs approval and certification by the competent health organizations, in order to commercialize safely in the Brazilian market. Thereby, they depend on the guidelines an ts complementary rules of the collegiate board of directors in the Nacional Health Surveillance Agency (ANVISA) and Health Ministry (MS) at national level; in a state level, the standard are secured by the State Secretary of Health (SES/SP) and municipal by the Health Surveillance (VISA). Objectives: The purpose of this abstract is to understand which are the regulator standard to manage a laboratory. By them, develop all quality system (SQ) documents in accord to the internal processes of fabrication and operation. All these documents are necessary to have a Technical Authorization Report (LTA), allowing a company located in São Carlos/SP to commercialize its products. Materials and Methods: To do so, the SQ management must be written in accord on the guidelines of the collegiate board resolution (RDC) $n^{\circ} 16 / 2013$ (Technica Regulation of good manufacturing practices for health products), $\mathrm{RDC} \mathrm{n}^{\circ}$ 02/2010 (Management of health technologies in health facilities) and RDC $n^{\circ} 306 / 2004$ (Technical Regulation for the management of waste of health services). These are the main national guidelines and, using them as base; it was written (i) Manual of Good Fabricating Practices (BPF); (ii) the Standard Operating Procedures for Specific Processes (POP-PE), (iii) of Equipment (POP-EQ), (iv) and ( the Equipment Management Plan (PGE). Results: From these documents, a physical adaptation project of the company has been created to suit the pattern of sections, people, processes and program, elaboration and evaluation of physical projects of health care establish tont). All program, elaboration and evaluation of physical projects of health care establishment). A In the end of the physical reform, all the documents are going to be reviewed and the VISA will

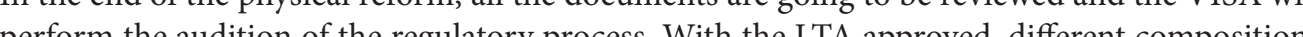
f $\mathrm{Ca}_{\mathrm{P}} \mathrm{P}$ will be produced and offered in the Brazilin manket. Conclusions: The importation

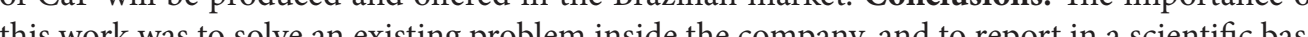

Journal homepage: http: www.journalamb.com/index.php/jamb

Towards an academic spin-offs maturity model

Creusa Sayuri Tahara Amaral ${ }^{1 *} ;$ Fernanda Yumi Sato ${ }^{2} ;$ Rafaela Rodrigues Santos ${ }^{2}$; Daniel Capaldo Amaral ${ }^{3}$

'Post-graduation Prog
University of Săo Paulo

ARTICLE INFO

Keywords:

Academics spin-offs

Maturity model

Entrepreneurship

ABsthact

The university has been challenged to include entrepreneurship inside the undergraduate and graduate programs, as a way to motivate new venture companies and innovation. This challenge is being faced by universities around the world. In Brazil, the teaching of entrepreneurship, in most institutions, follows the traditional method. This work aims to present an academic spinoffs maturity model, based on the model of Fiates et al. (2008), which is a representation of a business acceleration model. The Fiates model considers 5 fundamental factors to describe the spin-oft maturity levels, which are: the entrepreneur, the product, the capital, the market and the management. The proposal of this research aims to incorporte new diminsions for Fiates' maturity model. The research project foresees a review of the spin-offs maturity models, cited in the literature, and case studies of academic spin-offs for the identification of new dimensions of spin-off maturity model. The proposal model will have validated from comparative analysis. The paper discuss how to organize the teaching of entrepreneurship, in order to meet all the maturity levels of the academic spin-off, combining theory and practice, from the prospecting and technological application. This project will generate practical results, such as actions to foster results can be to contributing in the field of entrepreneurial university theory. 
Regulatory process of a bioceramic laboratory by the health surveillance guideliness

André Candido Porto ${ }^{1,2,} ;$ Fábio Trevelin Centanin ${ }^{2,3}$

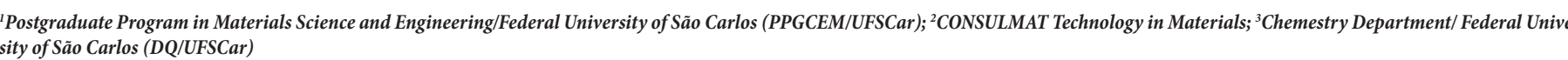
ARTICLE INFO

\section{Keywords:}

Regulatory Guidelines

Health Surveillance

Ceramic Biomaterials

Laboratory Management

ABSTRAC

Introduction: Biomaterials production companies, specially, bone grafts based in bovine bone mineral matrix $(\mathrm{CaP})$, needs approval and certification by the competent health organizations, in order to commercialize safely in the Brazilian market. Thereby, they depend on the guidelines an is complementary rules of the collegiate board of directors in the Nacional Health Surveillance are secured by the State Secretary of Health (SES/SP) and municipal by the Health Surveillance are secured by the State Secretary of Health (SES/SP) and municipal by the Health Surveillance standard to manage a laboratory. By them, develop all quality system (SQ) documents in accord standard to manage a laboratory. By them, develop all quality system (SQ) documents in accord have a Technical Authorization Report (LTA), allowing a company located in São Carlos/SP to commercialize its products. Materials and Methods: To do so, the SQ management must be written in accord on the guidelines of the collegiate board resolution (RDC) $n^{\circ} 16 / 2013$ (Technical
(T) Regulation of good manufacturing practices for health products), RDC no $02 / 2010$ (Management of health technologies in health facilities) and RDC $n^{\circ} 306 / 2004$ (Technical Regulation for the management of waste of health services). These are the main national guidelines and, using them as base; it was written (i) Manual of Good Fabricating Practices (BPF); (ii) the Standard Operating Procedures for Specific Processes (POP-PE), (iii) of Equipment (POP-EQ), (iv) and of Good Fabricating Practices (POP-BPF); (v) the Solid Waste Management Plan (PGRSS) and the Equipment Management Plan (PGE). Results: From these documents, a physical adaptation project of the company has been created to suit the pattern of sections, people, processes and raw material flow required by the VISA in the RDC $\mathrm{n}^{\circ}$ 50/2002 (Technical Regulatory to plan, program, elaboration and evaluation of physical projects of health care establishment). Alt documents were filed to VISA and, in a preview analysis, it was opened the regulatory process. In the end of the physical reform, all the documents are going to be reviewed and the VISA will perform the audition of the regulatory process. With the LTA approved, different compositions of $\mathrm{CaP}$ will be produced and offered in the Brazilian market. Conclusions: The importance of this work was to solve an existing problem inside the company, and to report in a scientific base the regulatory process, so that future entrepreneurs can use this method.
Journal homepage: http: www.journalamb.com/index.php/jamb

\section{Technological forecasting on additive manufacturing for bone tissue engineering in Brazil}

André Candido Porto ${ }^{1,2, *}$, Douglas Henrique Milanez ${ }^{3}$, Daniel Rodrigo Leiva ${ }^{3}$

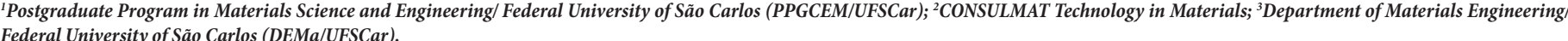
ARTICLE INFO

Keywords:

Additive Manufacturin

Bone Tissue Engineering

Scaffolds

ABSTRACT

A interion

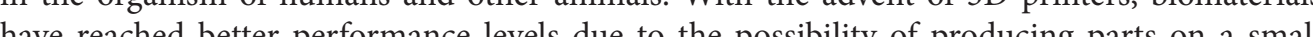

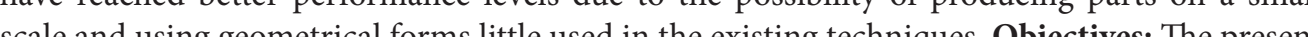
cale and describes the beginning of a technological forecasting study on additive manufacturing used in bone tissue engineering in the Brazilin context Materials and Methods. To this end, a search was made in the Web of Science database, using keyword combinations of three che (i) bone tisse enginering (ii) materials (in this case, as bone grating is the main goal, calcium phosphates were used such as Hydroxyapatite) and (iii) additive manufacturing The results were processed using the VantagePoint v. 5.0 software in order carry out a bibliometric andysis of the records retrieved. Results A total of 720 articles from 44

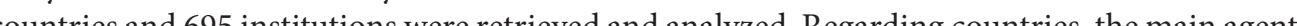
in the scene of tridimensional printing in bone grafting are China (24.1\%), the USA $(20.8 \%)$ and Germany $(13.6 \%)$ while Brazil is in 18th phace, with 14 articles published (1.94\%). In Brazi, he beging (13. (UNICAMP - SP) and reached its peak in 2013 with 4 publications, and the Federal University of Rio Grande do Sul (UFRGS - RS) continues to be the main producer of knowledge. Of the 14 ticles published in Brazil 35.7\% were with international participation from Belgium, Jpan Portugal, Spain, Switzerland, the USA, Germany and Italy Conclusions: This data describes Brazil as not being influencing country on this technique. Furthermore it has been shown to be an emerging process in countries that have an established tradition in technological production. It should be observed that, while the first studies of using 3D printing in bone grafting dates from the end of the 1980s, in Brazil, it only began 20 years later. Therefore, this study shows delay in Brazil regarding this technology application. In order to gain more conclusions about this topic worldwide and in Brazil, other routes of datamining must be followed. This should be done in future work considering other databases, particularly in the areas of engineering and biomedicine, as well as using specific patent databases. 


\section{International Journal of Advances in Medical Biotechnology}

Journal homepage: http: www.journalamb.com/index.php/jamb

Science awareness coffee: a contribution to the development of the entrepreneurial ecosystem with researchers from Araraquara / SP.

Henrique Croisfelts ${ }^{1,} ;$ Hernane Barud da Silva

'UNIARA, Biopolmat

\section{ARTICLE INFO}

\section{Keywords:}

Academic entrepreneurship

Innovation in biotechnology

Entrepreneurial ecosystem

ABSTRAC

Introduction: Between 1987 and 2008 there was a growth of more than one thousand percent in the number of doctorate graduates in Brazil. However, in order to reach proportions similar to that of developed countries, a 4.5-fold increase in the participation of PhDs in their populatio would be necessary. On the other hand, there is an alarming fact: formation of cadres to meet the demands of the postgraduate degree itself no longer accounts for absorbing the picture formed. In 2007 and 2008, 39.8\% of the recent doctors did not were found as employees. In view of this state of af been seen is that the higher the degree, the lower the level of entrepreneurship. It seems that undertaking is a synonym of abandoning the academic career, but in several centers of academic excellence, actions are being put into practice to bring the academy closer to the market: Leader in innovation fellowships of the University of Oxford, Babson College and also the creation of several Science Parks in all the state of Săo Paulo. The process of creation of a company has a complex character and is linked to a set of social, culf it is nd econonic factors. To raise the success rate of academic entrepreneurship activities it is necessary to establish motivation mechanisms for students with Entrepreneurship potential. Entrepreneurial capacity refers to a type of hinan capital that comprises the set of knowed resources and skills, which are

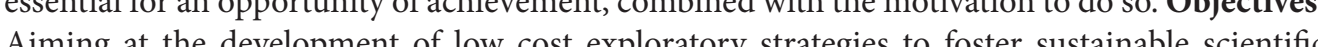
Aiming at the development of low cost exploratory strategies to foster sustainable scientific chese warthly to choose and discuss topics of common interest to inprove their kills. Some of the questions include: "How much is my idea, innovation or compny worth?"; "What is the best legl and tax aspect to initiate an enterprise" "What is the buredric

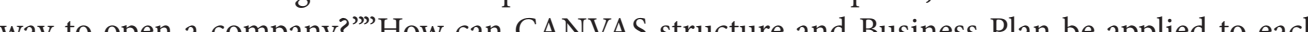
innovatio?" Conclusions: Based on these questions, approaches have been promed to vacis partners, such as CANVAS workhops and the construction of various public com toviction pelch partnerships, expanding the local entrepreneurial ecosystem.

Financial support: CAPES.

\section{INTERNATIONFL SYMPOSIUM \\ of Medicinal Chemistry and Regenerative Medicine}

NOVEMBER 22"10 TO 24"H, 2017

Araraquara/SP - Brazil

$\triangleright$ Regenerative Medicine - Abstracts 


\section{International Journal of Advances in Medical Biotechnology}

Journal homepage: http: www.journalamb.com/index.php/jamb

Biomodulatory influence of low-intensity laser therapy and serum rich in growth factor inhuman fibroblasts cells

Matheus Henrique Rondine ${ }^{1 ;}$; Nivaldo Antônio Parizzoto ${ }^{1}$; André Capaldo Amaral

University of Araraquara- UNIARA

\section{ARTICLE INFO}

\section{Keyword}

Tendon

Tendinopathy

Platelet-rich plasma

Low-intensity laser therapy

\section{ABSTRACT}

Introduction: Low-intensity laser therapy (LILT) and serum rich in growth factor (SRGF) derived from the human platelet-rich plasma technique (hPRP) are clinically used as biostimulant agents in tissue repair. The use is justified by the ability to stimulate cell proliferation an differentiation, the synthesis of extracellular matrix components and local neoangiogenesis. On the other hand, the effectiveness of these techniques, as well as administration parameters, are not properly established. Objectives: Thus, the present study aimed to characterize, in an in-vitro condition, the biomodulatory influence of both techniques on human fibroblas cells. Materials and Methods: Samples of blood from a male volunteer were centrifuged for fractionation of platelet-rich plasma and activated with calcium chloride $(10 \% \mathrm{~m} / \mathrm{v})$ to obtain SRGF. Human fibroblasts (line GM07492) were seeded in 24-well plates ( $5 \times 10^{4}$ cells) in DMEM culture medium supplemented with 2.5\% SRGF or fetal bovine serum (FBS). The groups related to LILT evaluation were submitted to laser radiation at wavelengths $(\lambda)$ of $685 \mathrm{and} 830 \mathrm{~nm}$. Doses of $0.3,0.6,0.9,1.2$ and $1.5 \mathrm{~J} / \mathrm{cm}^{2}$ with power density of $18 \mathrm{~mW} / \mathrm{cm}^{2}$ were evaluated. The cell viability were determined by the MTT-Formazan colorimetric assay 24 hours after irradiation and expressed as percentage of viabilty of control group (DMEM+2.5\% FBS). The results were Fisher's post-test. Results: Comparison of cell viability between the group using FBS by Fisher's post-test. Results: Comparison of cell viability between the group using $\mathrm{FBS}$ and the growth factors sources. Regarding LIIT, both $\lambda$ showed biomodulatory potential between fbroblast viability although the effective dose type and intensity of modulation wa significt different Radition at $\lambda 685 \mathrm{~nm}$ provided $40 \%$ increase in viability at don were significantly of $830 \mathrm{~nm}$ resulted in $60 \%$ in prease in viability at the dose of $0.3 \mathrm{~J} / \mathrm{cm}^{2}$ and a reduction of $15 \%$ and $10 \%$ at the doses of 0.9 and $12 \mathrm{~J} / \mathrm{cm}^{2}$, respectively. This biomodulatory influence was not modified by he PRP-derived growth factors. Conclusions: These results dence was not

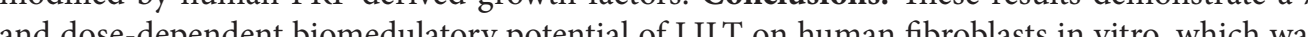

Financial support: CAPES

Introduction: Rats induced to polycystic ovaries (PCO) present ovarian alterations in both folliculogenesis and steroidogenesis. There is a reduction in the number of follicle and corpor lutea in addition to appearance of folliclecysts. Hyperandrogenemia is a consequence of steroidogenic alterations which induces irregular estral cycles. Low-level laser therapy (LLLT) the The do biomodulating influences on cellular functions both in vivo and in vivo. Objectives: in PCO 250 induced by injectided into control $(\mathrm{n}=15), \mathrm{PCO}(\mathrm{n}=15)$ and $\mathrm{PCO} / \mathrm{aser}(\mathrm{n}=15)$. $\mathrm{PCO}$ rats were rats were divided into 30,45 and 60 days after injections. The animals were manually contained and irradiated with laser at the wavelength of $808 \mathrm{~nm}$, with power between $60 \mathrm{~mW}$, in a dose of Joules (J)/ point, for 18 seconds on the dorsal region, performing a transillumination on each rificer the a week, totaling $6 \mathrm{~J}$ of energy per irradiated animal/per day of application. After lides. The ondtes were collected for preparation and subsequent analysis of the histological means of the treatment ( reported as the means \pm SEM. Results: The results showed that the largest number of follicles PCO number of follicles compared to the PCO group and equal to the control group. Conclusior The results allow us to conclude that the use of LLLT increased the number of ovarian follicles in the PCO-induced rats apparently restoring the ovarian activities of folliculogenesis. 


\section{International Journal of Advances in Medical Biotechnology}

Journal homepage: http: www.journalamb.com/index.php/jamb

Resistance exercise can promote morfofunctional changes in ovary polycystic-induced rats

Vilson Donizete Matias ${ }^{1 * *}$; Ana Lúcia de Oliveira Bonfá,; Jorge Alberto Achcar'; Luís Henrique Montrezor ${ }^{1,2}$

Biotechnology - Regenerative Medicine and Medical Chemistry - UNAARA, Araraquara, SP, Brazili, 'Departament of Biological Science and Health - Medicine - UNARA, Araraquara, SP, Brazil ARTICLE INFO

\section{Keywords:}

Polycystic ovary

Resistance exercise

Metabolism

Body weight

Introduction: Polycystic ovary syndrome (PCOS) is a heterogeneous syndrome characterized by an ovulation, clinical and/or biochemical signs of hyperandrogenism and abnormal ovary morphology. Rats induced by polycystic ovary (PCO) presents structural and functional ovary modifications that compromise the estrous cycle. The induction of PCO in rats using Estradio Valerate (EV) is an interesting model because it develops ovarian alterations similar to PCOS in women. Objectives: The objective of this study was to identify possible changes in body weight, ovarian weight, gonado somatic index (GS) and maximal voluntary carrying capacity (MVCC) at the end of the training in $\mathrm{PCO}$-induced rats submitted to resistance exercise. Materials and Methods: Forty female adult Wistar rats weighing $200 \mathrm{~g}-300 \mathrm{~g}$ were divided into 2 group: 30 days $(\mathrm{n}=20)$ and 45 days $(\mathrm{n}=20)$ after PCO induction, and these groups were divided into 4 subgroups: control ( $(\mathrm{n}=5), \mathrm{PCO}(\mathrm{n}=5)$, control/training $(\mathrm{n}=5)$ and PCO/training $(\mathrm{n}=5)$. The PCO induction was performed with a single dose of $\mathrm{EV}(2 \mathrm{mg} / 0.2 \mathrm{~mL} /$ rati.m.). The resistance exercise chosen was stair climbing ( 3 times/week) with loads added to the tails of the rats. The data were analyzed using ANOVA and Tukey's test. Significant statistical differences among the means of the treatment groups were decided for $\mathrm{p}$-values $<0.05$. This study was approved by local Anima Care and Use Committee (CEUA-UNIARA, protocol $\mathrm{n}^{\circ} 025 / 16$ ). Results: For the 30-day group: the left ovary weight was higher for the control group $(0.09708 \pm 0.015 \mathrm{~g})$ compared to the $\mathrm{PCO}$ training group $(0.06904 \pm 0.0123 \mathrm{~g}$ ). For the 45 day group: the body weight of the control group $(367.2 \pm 18.3 \mathrm{~g})$ was greater than the $\mathrm{PCO}$ group $(274.8 \pm 18.47 \mathrm{~g})$ and the $\mathrm{PCO} /$ training grou $(290.8 \pm 20.52 \mathrm{~g})$. The $\mathrm{PCO}$ /training group had a lower body weight than the control group. For the 45 -day group: the right ovary weight of the control group $(0.0584 \pm 0.0129 \mathrm{~g})$ was greater MVCC $\mathrm{CO}$ group $(0.0276 \pm 0.0063 \mathrm{~g})$. There was no statistical diference for elther IGS or MCC. Conclusions: The PCO-induced rats by EV is a viable model for studies that correlate

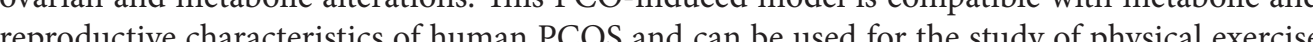

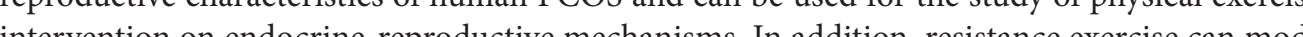
the

\section{International Journal of Advances in Medical Biotechnology}

Journal homepage: http: www.journalamb.com/index.php/jamb

Development and evaluation of lamelar denso scaffold for tissue engineering

Thais Francine Ribeiro Alves ${ }^{\prime \prime} ;$; Katiusca da Silva Pontes'; Juliana Ferreira de Souza'; Mirella Sever'; Marco Vinicius Chaud

Laboratory of Biomaterials and Nanotechnology - University of Sorocabe

\section{ARTICLE INFO}

Keywords:

Acute myocardial infarction

Tissue engineering

Lamellar scaffold

Biopolymers

Collagen

\section{ABSTRACT}

Introduction: Acute myocardial infarction (IAM) continues being responsible for the reduction in life expectancy and large numbers of deaths worldwide. Tissue engineering for cardiac tissu regeneration has been an alternative to restore the structure and mechanical functionality of the heart. Scaffolds are porous three-dimensional support, temporary, used to mimic the structure of the extracellular matrix and stimulating specific cellular responses at the cellular level / molecular organic tissue for regeneration. Objective: To project, to development and to evaluate dense amellar scaffolds with potential use in tissue engineering. Materials and Method: The hydrogels, for fabrication of scaffolds, were prepared by mixture of collagen, chitosan and Poloxamer 407. Scaffolds for AMI were produced by plastic compression (using hydrostatic press). Briefly, cas highly hydrated hydrogels were transferred to a porous support comprising (bottom to top) absorbent paper blot layers, a steel mesh and wo nylon meshes. The matrices were freeze-dried, resulting in cross-linked collagen-chitosan scaffolds. The samples were evaluated by swelling efficiency, porosity, interconnectivity and pore size, Fourier transform infrared spectroscopy and physiomechanical properties. Results. The physical mechanism controlling solute uptake was observed as anomalous transport, with the n values equal 0.79 . The scaffold showed high interconnectivity of the porous with $71.68 \%$ of the porosity. The pore dimensions estimated from SEM microphotographs for scaffold was in the range of $15-25 \mu \mathrm{m}$. The FTIR spectrum of the blend polymers shows the characteristic bands of the parent molecules. No additiona bans were identifed indeating that did not have chencal interaction between the polymers used in the formulation. The results of physiomechanical properties like as elasticity, flexibilty $1.806 \pm 0.058 \mathrm{~N}$ and $0.648 \pm 0.040 \mathrm{~N}$ respectively Conclusio 1.806 the by the blend of collagen and chitosan, by plastic compression, showed promising feature in the
application of the tissue engineering. 
Characterization of collagen and evaluation of potential use as gel in tissue engineering

Thais Francine Ribeiro Alves ${ }^{1 ;}$; Katiusca da Silva Pontes ${ }^{1}$; Fernando Batain'; Marcia Rebelo'; Cecília Torquetti'; Marco Vinicius Chaud

Laboratory of Biomaterials and Nanotechnology - University of Sorocaba

\section{ARTICLE INFO}

\section{Keywords:}

Collagen

Biopolymers

Tissue engineering
Introduction: Collagen is the most abundant protein in the extracellular matrix and has been considered to be a group of proteins with a fibrillar structure, which contributes to the extracellular scaffolding. In the presence of acid, alkalis and saline aqueous solutions a considerable increase in the ane collagen is in the range of 6.5 to 8.5, and any deviation from this $\mathrm{pH}$ (i.e. Change in the isoelectric point) may cause non-specific swelling. Objective. To investigate the diference between chen engingering. Materias and Method. The Fourier transform infrared spectroscopy (FTIR). The ( 7,4 and 2 ( Py water holding capacity (WHC) and gelation temperature (Tsol-gel) be gels $3.8^{\circ} \mathrm{C}$. Reated 列 Then chemical groups showed by $\mathrm{CF}$ and $\mathrm{CP}$ we comptible with literature. Collagen behavior at low temperatures, that is, with the increase in the temperature occurs the decrease f the gel viscosity therefore, the gel collogen shows Trel-sol (transition tempers of solution). The arenge value for WHC of the CP and CF was 92\% of initial mass of the gel. (a) $1 \%$ of collagen did not occur Tsol- el, the preparation keep itself gelled in all temperatures $\mathrm{C}$ showed Tgel-sol at $23^{\circ} \mathrm{C}$ to $0.75 \%$ in water, $17^{\circ} \mathrm{C}$ to $0.5 \%$ in sodium phosphate medium and $33^{\circ} \mathrm{C}$ to $0.5 \%$ in acetic acid. $\mathrm{CP}$ in water showed Trel-sol at $22^{\circ} \mathrm{C}$ and $31^{\circ} \mathrm{C}$ for $0.50 \%$ and $0.75 \%$, re spectively $\mathrm{CP}$ in sodium phosphate showed Tgel-sol at $11^{\circ} \mathrm{C}$ and $21^{\circ} \mathrm{C}$ for $0.50 \%$ and $0.75 \%$, acetic acid medium the Tgel-sol was observed only to the $0.50 \%$ concentration of the CP. Conclusion: The medium used to prepare the $\mathrm{CP}$ and $\mathrm{CF}$ gels influenced significantly the Tgel-sol behavior. The concentration of $\mathrm{CP}$ or $\mathrm{CF}$ can be modulated in an attempt to achieve the Tgel-sol proper. The $\mathrm{CP}$ and $\mathrm{CF}$ gel shows potentil use in tissue engineering as injectable gel and in the scaffold fabrication
Journal homepage: http: www.journalamb.com/index.php/jamb

PLA (polylactic acid) scaffold printed by $3 \mathrm{~d}$ tecnology and functionalized by plasma of oxygen

Lorenzo Gouvêa Machado ${ }^{1 *} ;$; Elidiane C. Rangel³; Sandra Cruz ${ }^{2}$; Mônica Rosas da Costa Iemma ${ }^{1}$; Hernane S. Barud

'UNIARA (Universidade de Arraraquara); 'UFSCAR- Quimica (Universidade Federal de Säo Carlos); ${ }^{3}$ UNESP - Quimica (Universidade do Estado de Säo Paulo) campus Sorocaba.

\section{ARTICLE INFO}

Keywords:

Polylacticacid

3 D printing

Plasma treatment

Introduction: The purpose of tissue engineering is to repair, replace, create or regenerate tissues and organs. Tissue engineering depends on a triad composed of cells, scaffolds or structures, polymers, and growth factors. Nowadays, it is necessary to use the biomaterial that allows tissue engineering to build and shape through 3D technology to support cells, repair organs with biocompatibility, and chemical and physical properties that allow the surface to work. Among the polymers, we can use PLA (polylactic acid). PLA has physical properties as well as biodegradability and bioconpatibity. Thus, the PLA has characteristics necessary for the manufacture of a scaffold. The scaffold is a support or structure that allows there generation of tissues. To create a scaffold, we use rapid prototyping. This new field of research is a versatile technique for generating large quantities of shapes and sizes of polymers. Three-dimensional (3D) printing, also known as the manufacture of additives (AM), extrudes the polymeric material into layers. Rapid prototyping (RP) represents the direct manufacturing of pieces per layer, guided by digital information from a computer-aided design (CAD) file without any specific part tool. To promote and increase properties such as hydrophilicity, adhesion, and proliferation, on the surface of the scaffold, we must work the surface with oxygen plasma. Objectives: The goal of this study is to develop polylactic acid scaffolds printed by 3D printing (PLA) by superficially functionalizing the scaftold with oxygen plasma for required fixation and growth of osteocyte cells. Materials and Methods: To achieve the scaffold we used FDM 3 D printer (Fused Deposition Modeling), called (Boa Impressão 3D), model Stella, Curitiba-PR, Brazil. The scaffolds were modeled (10 $\mathrm{mm}$ in diameter $x 1 \mathrm{~mm}$ in height) in Autodesk Inventor CAD software and exported in the forTo incre The Mortech fla we with a dianeter of $1.75 \mathrm{~m}$ mas used for the extrusion of PLA. To increase the roughness, we used the functionalization of the oxygen plasma on the surface of he scafold. The system consists of a stainless steel reactor $\left(\sim 5.2 \times 10-3 \mathrm{~m}^{3}\right)$ containing two par-

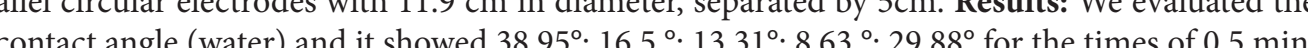
$1 \mathrm{~min}, 5 \mathrm{~min}, 10 \mathrm{~min}$ and $20 \mathrm{~min}$ respectively. Analyzing these results from the contact ang were alized that the function lization through. Analy the PLA surface. We used AFM atomic force microscopy to investigate surface roughness and the the functionalized scaffold to the proliferation and viability test with $1 \times 10^{5} \mathrm{O}$ steo- 1 cells seeded in DMEM environment for 72 hours. We achieved $89 \%$ of proliferation. We also noticed that

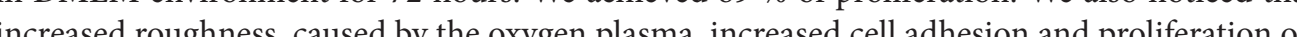

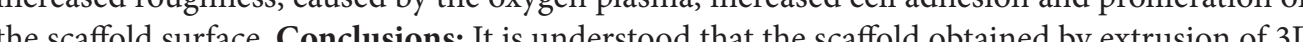
printing with PLA and the functionaliztion with oxygen plasma promotes a better contro of shape and size of the organ or tissue to be built, and imitates the extracellular matrix.

Financial support: CAPES

Corresponding author 
Journal homepage: http: www.journalamb.com/index.php/jamb

The use of stem cells as a promising method for cardiac regeneration: current scenario and future prospects Matheus Lopes Puls ${ }^{1, *} ;$ João Clima da Silva ${ }^{1,2}$

"University of Araraquara: 2 Syrian-Lebanese Hospitat

\section{ARTICLE INFO}

\section{Keywords:}

Stem Cells

Heart

Regeneration

ABSTRACT

Introduction: Once cardiovascular diseases are the main cause of global mortality, there is high interest in the development of therapies for the reduction of the impact of these pathologies. The use of Stem Cells (SC) as a therapeutic method is a recent tactic for cardiac regeneration, justifying reviews about its current and future use. This technique is promising because it is able to provide cardiomyocytes after ischemic events, induce revascularization of the damage area, and prevent deleterious pathological remodeling. Objectives: Analyze, through specialized literature review, the current scenario and future perspectives of the use of SCs for cardiac regeneration focusing obstacles and strategies of study. Materials and Methods: Articles from the last 6 years (2011 to 2017) were searched in the databases MEDLINE (accessed via PubMed), SciELO, LILACS, Scopus and Cochrane Library in English and Portuguese. The descriptors were Stem, Cell, Cardiac, Heart, Regeneration, Repair and Therapy. Initial selection of articles was carried out based on the titles and abstracts and, after verification of the appropriate content, the complete text was searched. Thus, 55 articles that approached the theme were obtained. After reading, 23 texts that fully answered to the objectives of this research were selected. The most recent articles, with the highest impact factor and level of evidence were prioritized. Case reports and opinion articles were excluded. Results: The current scenario of SC implantation for cardiac regeneration is still little explored. The reviewed articles lists as difficulties in the study of the subject: heterogenic groups and methodologies, low long - term clinical follow - up of the volunteers and restricted number of works due to difficult access to suitable material and case - control groups. Not all types of SCs have already been studied. As obstacles to therapeutic applications, studies found that undifferentiated SCsmay induce teratomas and karyotyp anomalies, genetic and immune rejection, immature phenotype (implanted cells tend to be more similar to their fetal counterparts), heterogeneity of SCs subtypes, and the difficulty of producing suficient cells for effective repair. As control strategies, $S$ C reprogramming techniques with nonviral vectors are being employed to avoid possible teratogenic events, addition of retinoic acid and and culture systems based on bioreactors to obtain adequate amount of cells. Combined gene and cell procedures are being und and a cerch as cardiac patches in vitro, engineered heart tissue and injectable scaffolds. Conclusios: SC technology is an attractive anproach to the generation of cardiac tissue, but studies foce

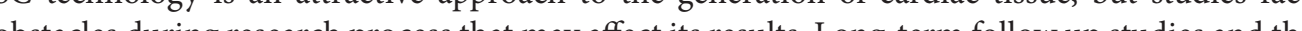
development of combined gene and cell procedures can change this scenario.
International Journal of Advances in Medical Biotechnology

Journal homepage: http: www.journalamb.com/index.php/jamb

Influence of type 2 diabetes mellitus on cardiac regeneration after ischemic cardiomyopathy

Matheus Lopes Puls ${ }^{1, *}$; João Clima da Silva ${ }^{1,2}$

University of Araraquara:2Syrian-Lehanese Hospitte

\section{ARTICLE INFO}

Keywords:

Diabetes

ABSTRACT

Antuction: Cardiovascular pathologies are the main cause of worldwide mortality. These $\mathrm{d}$ (T2DM) is ant an estimated $80 \%$ of all deaths in diabetic patients. Once type 2 diabetes mellitu (12DM) is an expanding global health problem, there is high interest in the understanding of well as development of appropriated therapies. Objectives: Analyze, through specialized literature review, the posible inoprentions the negative effects of T2DM, focusing its $p$ he ture review, he possible interventions against the negative effects of T2DM, focusing its physiMethods: Articles from the last 7 years (2010 to 2017) were searched in the daty. Materials and

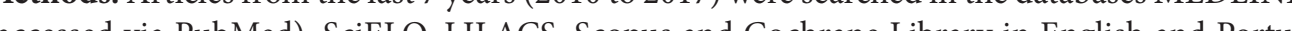
(accessed guese. The Initial selection of articles was carried out based on the titles and abstrats fter verification of the appropriace content the complete text was searched. Thus 35 articles tha a p this research were selected. Most recent articles, with the highest impact factor and level of evidence were prioritized. Case reports and opinion articles were excluded. Results: The elevated erces pratimited numbr of patients and pre-clinical diabetic models. Some studies showed that mesenchymal stem cells (MSC) infused into diabetic rats with diabetic cardiomyopathy improved their heart function, lowered serum glucose and increased serum insulin levels compred with the control diabetic group (possbly through angiogenesis and attenuation of cardiac red with ing). It was noticed that MSC therapy promoted effective cardiac nerve sprouting enhanodediomyocyte proliferation and increased endothelial cell incorporation into neovascularization, reducing heart complications in the presence of T2DM. However studies also pointed that in specific situations. T2DM inhibited the multipotency of MSCs and impaired their sufficiency to increase blood flow recovery. Hyperglycemia also showed deleterious effects on the role of endothelial progenitor cells in vascular and tissue repair, as well as affected the migration of cardiac SCs. On possible strategies to prevent or reverse the deleterious diabetic effect on SCs and cardiac regenerative therapies, articles suggest control of hyperglycemic state, reversal of oxidative stress, cardiac niche enhancement (to recover the cardiac homing capacity of SCs) and molecular modulation of specific targets (such as $\mathrm{p} 38 \mathrm{MAPK}$ and ERK1/2). Conclusions: The association of T2DM and cardiac diseases is relevant and a global health problem. The understanding of its physiopathological aspects can lead to better treatment options. Cardiac regeneration after ischemic cardiomyopathy with SCs is a promising therapy, still in development, that will require adaptations when applied to T2DM patients. 


\section{International Journal of Advances in Medical Biotechnology}

Magnetic resonance imaging parametrization for threedimensional biomodels printing of patella joint cartilage

Fernando Pereira Vanni ${ }^{1 *} ;$; Marcello Henrique Nogueira-Barbosa ${ }^{2} ;$ Airton Moreira da Silva $a^{3} ;$ Amanda Amorin Nunes ${ }^{3}$; Rodrigo Alvarenga Rezende ${ }^{3}$; Jorge Vicente Lopes da Silva³; André Capaldo Amaral

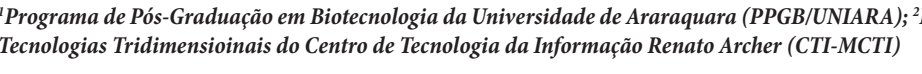

\section{ARTICLE INFO}

\section{Keywords}

Magnetic resonance imaging

Parameterization

Patellar cartilage

ABSTRACT

Introduction: One of the most important causes of reduced body movement is osteoarthrosis $(\mathrm{OA})$, the knee joint is the most involved and a fundamental component of this joint is patellar cartilage. Cartilaginous lesions lead to OA, fast or insidious, resulting from genetic, traumatic, vascular and metabolic alterations, leading to the irregularity of its surface and reduction of its thickness, aspects to be studied in detail. The spatial view of cartilage defects, as well as the monitoring of disease progression are of fundamental importance for the effectiveness of the treatment. It is not common to surgeons the three-dimensional (3D) idea of parts of the human body in the study and planning of conservative (clinical) and surgical treatment. Objectives: The objective of this research is to establish a higher quality parametrization for the acquisition of magnetic cartilage through 3D printing technology. Materials and Methods: For this, a healthy individual, female, 25 years old and with no orthopedic antecedents or complaints compatible with patellar chondropathy was evaluated. The patient underwent magnetic resonance imaging of the knee in Magneton Essenza 1.5T equipment (SIEMENS ${ }^{\circ}$ ) coupled to a 14-channel radio-frequency coil. Axial images were established from the acquisition sequences T2-Gradiente, Proton Density (DP), T1- SpinEco, T1-Vibe and T2-GradienteEco (T2-GRE). The images were processed in the software InVesalius ${ }^{\circ}$ and Magics ${ }^{\circ}$ for the construction of three-dimensional biomodels in virtual environment. The recommended acquisition parameters for the generation of 3D biomodels of the patellar articular cartilage were established through a comparative analysis between the different acquisition sequences, considering the time spent in the image processing and the accuracy achieved in the virtual biomodels. Results: The results showed that all acquisition sequences allowed the generation of the 3D biomodels. In contrast, the processing parameters, the time spent performing the processing and the accuracy reached in the biomodels were significantly different among them. The best performance was achieved with the T1-Vibe acquisition sequence, which provided the shortest processing time and the highest accuracy of the three-dimensional biomodel. Conclusions: It is concluded that the parameters associated with this acquisition sequence ar recommended for obtaining magnetic resonance imaging for the preparation of three dimensional biomodels for 3D printing. New research will be conducted to investigate the influence of other acquisition parameters, such as the field strength of the main magnet and the technical characteristics of the radiofrequency coil.

\section{ITERRMTIONHL SYMPOSIUM \\ of Medicinal Chemistry and Regenerative Medicine}

\section{NOVEMBER $22^{\text {MO }}$ TO $24^{\text {TH }}, 2017$}

\section{Araraquara/SP - Brazil}

\section{$\triangleright$ Medicinal Chemistry - Abstracts}


Evaluation of the kinetic profile of the release of tetracycline in simulated gastric fluid and simulated intestinal fluid from biopolymer microparticles

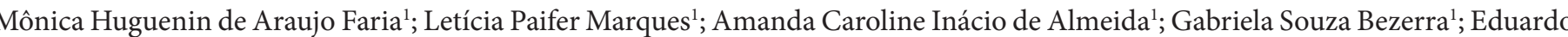
Santana da Silval. Francisco Benedito Teixeira Pessine

${ }^{i}$ Institute of Chemistry, State University of Campinas, Campinas, Brazil

\section{ARTICLE INFO}

\section{Keywords:}

Alginate

Chitosan

Drug Delivery System

Tetracycline

Polyelectrolytes

ABSTRACT

Introduction and Objectives: The aim of this paper was to prepare and characterize biopolymeric microparticles (MP) with bioadhesive properties to promote the sustained antibiotic release. The development of such devices aims to prevent early disruption of treatment protocol with antibiotics caused by lack of adherence from the patient, whose disruption is one of the causes of bacterial resistance increase. Materials and Methods: MP were prepared through mechanical shearing of chitosan $(\mathrm{CH})$, sodium alginate $(\mathrm{SA})$, and tetracycline hydrochloride (TC), whose amount followed an experimental design $2^{3}$, whereby an influence of each component was oberved in properties such diameter $(\mathrm{D})$, encapsulation efficiency $(\% \mathrm{FE})$, and loading percentage $(\% \mathrm{LP})$. Diameters were measured on the Malvern Mastersize 2000 equipment. It was obtained particles with diameters between 4.5 and $8.5 \mu \mathrm{m}$ were obtained. \%EE was calculated through the relation between the difference of the total mass of $\mathrm{TC}\left(\mathrm{TM}_{\mathrm{TC}}\right)$ and the free mass of TC ( $\mathrm{FM}$ and $\mathrm{TM}_{\mathrm{TC}}$. And $\% \mathrm{LP}$ was calculated through the relation between the difference of the $\mathrm{TM}_{\mathrm{TC}}$ and the $\mathrm{FM}_{\mathrm{TC}}$ and the total mass of polymer. $\mathrm{FM}_{\mathrm{TC}}$ was obtained through the liquid extracted by centrifugation at 10000 RPM for 10 minutes of $500 \mu \mathrm{L}$ of MPs suspension placed in a ultrafiltration device Amicon ${ }^{\circ}$ Ultra 0,5 MWCO 100K. TC was quantified by High performance liquid chromatography (HPCL) according to the Pharmacopoeia method of United Stated (USP 30 - NF 25, 2007). Results: \%EE differed between 56\% and 87\% and \%LP between 19\% and $87 \%$ Reagents and microparticles were characterized as to main functional groups identification by Fourier Transform infrared spectroscopy (FTIR); as to thermal stability by Differential Scanning Calorimetry (DSC). DSC tests indicated that preparations have less thermal stability with respect to pure reagents. FTIR spectra were recorded in the Fourier transform spectrometer, Agilen Cary, model 630 FTIR, with module ATR. FTIR spectra indicated the interaction between the $\mathrm{CH}, \mathrm{SA}$, and TC functional groups, which intensity differed according to the ratio of these compounds and affected both, loading percentage and encapsulation efficiency, as well as the releas profile. Sustained release profile of TC in simulated body fluid with different PHs (simulate gastric fluid (SFG) and simulated intestinal fluid (SFI) were observed by $2 \mathrm{~h}$ and $48 \mathrm{~h}$, respectively. These results suggest that there is a decrease of the burst effect in the TC release in both SFG and SFI, avoiding that the initial dose reaches a toxic level. Release profile in SFG is different tha the observed in SFI, expected result, once the matrix constitutes of polyelectrolytes, which are sensible to the PH of solution. Conclusions: These results indicate that some microparticles are promising to a final formulation.
Journal homepage: http: www.journalamb.com/index.php/jamb

Cytotoxic and mutagenic effects of new $\mathrm{Cu}(\mathrm{II})$ complex as potential antituberculosis agent

Nathália Ferreira Fregonezi ${ }^{1 *}$; Fabiana Aparecida de Souza ${ }^{1}$; Mariana Barreto ${ }^{1}$; Patrícia Bento da Silva ${ }^{2}$; Flávia Aparecida Resende

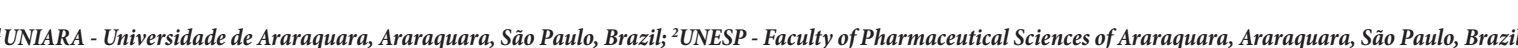

ARTICLE INFO

Keywords:

$\mathrm{Cu}(\mathrm{II})$ complexes

Ames test

Micronucleus test

Cytotoxicity

BSTRACT

Introduction: Since the discovery of the cytotoxic and antitumor activities of cisplatin, medicinal chemistry has seen impressive advances in the bioinorganic chemistry, with a growing interest in he study of the biological activities of metal complexes. In this context, copper $(\mathrm{Cu})$ has a number of qualities that have made it attractive for such research, as it operates as a first-row transition metal, is the third most abundant trace metal in the human body (behind iron and zinc), is important for plants, animals and fundamental to the performance of several enzymes involved in energy metabolism, respiration, and deoxyribonucleic acid (DNA) synthesis. Previous studies showed that $\mathrm{Cu}(\mathrm{II})$ complexes, formed from the interaction of $\mathrm{Cu}$ (II) ions with biologically active ligands, have shown excellent antimicrobial activity against $M$. tuberculosis. Objectives: In view of this antimycobacterial activity and its potential as a lead compound for drug development the aim of the present study was to investigate the mutagenic activity of $\mathrm{Cu}$ (II) complex with isoniazid $\left.\left[\mathrm{Cu}(\mathrm{NCO})_{2}(\mathrm{INH})_{2}\right]_{4} 4 \mathrm{H}_{2} \mathrm{O}(\mathrm{I} 3)\right]$, by the Ames test and the micronucleus assay, to assess the safe use of this complex in the treatment of tuberculosis, besides the cytotoxic activity in normal cell line (GM-07492 - human lung fibroblasts) and a cell line with metabolism profile of carcinogens (HepG2) by MTT (3-(4,5-dimethylthiazol-2-yl)-2,5-diphenyltetrazolium bromide) Sciences of Araraquara and provided by Dr. Patrícia Bento da Silva. The Ames test was performed using TA98, TA100, TA97a and TA102 strains of Salmonella typhimurium, as sensitive indicator of DNA damage, in the absence $(-59)$ and presence $(+S 9)$ of metabolic activation system in five concentrations, varying from 15.6 to $250 \mu \mathrm{g} / \mathrm{plate}$. The micronucleus assay was performed in HepG2 cells in 3 different concentrations of I3, varying from 125 to $500 \mu \mathrm{g} / \mathrm{mL}$. Results: The results obtained by Ames test showed that I3 induces only signs of mutagenicity in strains TA100 and TA97a tested in presence of metabolic activation. Similarly, it was observed a chromosoma damage in HepG2 cells with significant increases of micronuclei and nuclear budsand. With respect to cell viability, the complex induced a concentration-dependent decrease, but even so, the cytotoxicity (IC50) was higher than $500 \mu \mathrm{g} / \mathrm{ml}$, indicating low toxicity. Conclusions: Further investigation is necessary to permit its more effective and safer use, beyond to clarify the mechanisms and the conditions that mediate the biological effects of $\mathrm{Cu}$ (II) complexes, before considering them as therapeutic agents.

Financial Support: UNIARA and FAPESP (2017/06317-7) 


\section{International Journal of Advances in Medical Biotechnology}

Journal homepage: http: www.journalamb.com/index.php/jamb

Nuclease activity of a copper complex with sulfameter

Douglas Hideki Nakahata ${ }^{1} ;$; Raphael Enoque Ferraz de Paiva ${ }^{1} ;$ Wilton Rogério Lustri²; Pedro Paulo Corbi ${ }^{1}$

Institute of Chemistry, UNICAMP, Campinas, Brazili'? University of Araraquara, UNIARA, Araraquara, Braz

\section{ARTICLE INFO}

Keywords:

Copper

Sulfonamide

Nuclease activity

ABSTRACT

Introduction: Copper complexes have a remarkable redox chemistry that has been explored for the development of artificial nucleases. The DNA damage is usually correlated to the anticancer and antibacterial activity of these copper compounds. Objectives. In this work, we report the nuclease activity of a copper(II) compound containing the sulfonamide sulfameter an 1,10-phenantroline as ligands. Materials and Methods: The copper compound was synthesized with 1:2:1 (copper(II) : sulfameter : phenantroline) ratio and characterized with chemical, spectroscopic and crystallographic techniques. For the evaluation of nuclease activity, two experiments were performed. Firstly, the plasmid pGEX4T-1 was incubated with the copper(II) complex and submitted to agarose gel electrophoresis. On the second experiment, ascorbic acid was added to the reaction mixture containing the plasmid and the compound. Copper(II) nitrate was also analyzed for comparison. Results: Results demonstrated that the complex alone alters the electrophoretic pattern of the plasmid, indicating some interaction, but no significant nuclease activity. Addition of ascorbic acid resulted in no visible band in the gel, indicating complete degradation of plasmid DNA at the complex concentration of $10 \mu \mathrm{mol} \cdot \mathrm{L}^{-1}$. Copper(II) intrate, howerer, of apercoiled an partially supecolde forms, but no complete degradaton was obsenved up to the concentratio of $20 \mu \mathrm{mol} \cdot \mathrm{L}^{-1}$. Conclusions: These results showed that the copper-sulfonamide is a promising compound for further biological studies.

Financial Support: FAPESP (grants 2015/25114-4, 2015/09833-0 and 2015/20882-3), CNPq grant 442123/2014-0) and CAPES.
International Journal of Advances in Medical Biotechnology

Journal homepage: http: www.journalamb.com/index.php/jamb

Palladium(II) and platinum(II) complexes with hydrazide derivative of nalidixic acid: synthesis and characterization

Carlos M. Manzano ${ }^{1 *} ;$ Fernando R. G. Bergamini'; Pedro P. Corbi

Inorganic Chemistry Department, Institute of Chemistry University of Campinas - UNICAMP PO Box 6154, 13083-970, Campinas.SP.Brazil

\section{ARTICLE INFO}

Keywords:

Platinum(II)

Palladium(II)

Nalidixic acid hydrazide

Spectroscopic analysi

BSTRACT

Introduction: Platinum-based drugs are one of the most effective classes of antitumor agents. Nowadays, the $\mathrm{Pt}(\mathrm{II})$ complexes approved as anticancer agents are cisplatin, carboplatin an oxaliplatin, and it is estimated that they are used in $50 \%$ or all cancer treatments. A great effor has been made to develop new metal complexes with tumor-inhibiting properties better than cisplatin and its derivatives in efficacy, selectivity, reduced toxicity and improved pharmacology. Despite the endeavors to treat cancer more effectively, the pace of drug development is far from the current increasing rate of cancer incidence and mortality. To improve this scenario, on strategy of drug discovery is to combine the cytotoxic properties of a metal ion with the desire features of a specific ligand that have favorable safety profile and known pharmacokinetics. Nalidixic acid (1-ethyl-7-methy-1,8-naphthyridine-4-one-3-carboxylate, nx) is considered the precursor of the antibacterial quinolone series and is a interfacial inhibitor of DNA gyrase protein in bacteria. The inhibition of such enzyme causes a preferential, rapid and reversible inhibition DNA synthesis. Objectives: In the present work, a modification of nx structure into a carbony hydrazide (hzd) was made and the obtained hydrazide was combined with Pt(II) and Pd(II) ion to further evaluate its antitumor activities. Materials and Methods: The hzd was synthesized from nalidixic acid following the procedure previously reported by our research group, and both complexes were sycthol is reacted with $0.50 \mathrm{mmol}$ of $\mathrm{K}_{2} \mathrm{PtCl}_{4}$ or $\mathrm{K}_{2} \mathrm{PdCl}_{4}$ in water, heated at $50^{\circ} \mathrm{C}$ for 2 hours under stirring

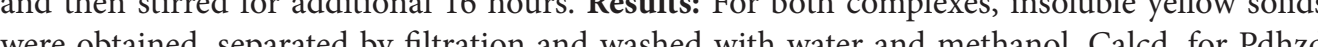
or $\mathrm{Pd}(\mathrm{C}, \mathrm{H}, \mathrm{N}, \mathrm{O}) \mathrm{Cl}(\%): \mathrm{C}, 43.03 \cdot \mathrm{H}, 4.21 ; \mathrm{N}, 16.73$. Found (\%): $\mathrm{C} 44.22 \cdot \mathrm{H}, 439 \cdot \mathrm{N}, 16.84$ Calch for Pthzd or Pt( . coordination of the ligand to the metal centers occurs by the $\mathrm{NH}$ group of hzd as the signal of the nitrogen atom of free ligand is shifted by -40.3 and $-37.7 \mathrm{ppm}$ in the Pdhzd and Pthzd complexes respectively Conclusions: This hypothesis is also supported by the infrad spectroscopic data of the complexes, where changes in the stretching modes of the $\mathrm{NH} 2$ group are observed. Biological studies are in progress.

Financial Support: CNPq Grants \#442123/2014-0 and \#140707/2013-1, FAPESP Grant \# 2015/25114-4 
Synthesis and cytotoxic activity on Pd(II) complexes containing thiosemicarbazide

Nathália Ariane Thomazella $a^{1 ;} ;$ Isabel Cristiane da Silva²; Carolina Valério Barra ${ }^{2 a}$; Fernando Rogério Pavan²; Antonio Eduardo Mau${ }^{1}$; Adelino Vieira de Godoy Netto ${ }^{1}$

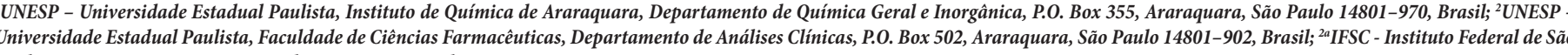

\section{ARTICLE INFO}

\section{Keywords:}

Pd(II) complexes

Thiosemicarbazide

IR and NMR spectroscopy

Medicinal chemistry

Antitumor activity

BSTRACT

Introduction: The interest on introduction of transition metal ions aiming at designing new chemotherapeutic agents has been prompted by the discovery of medicinal uses of cisplatin in treatment of several types of human neoplasms. Particularly, palladium(II) compounds have attracted considerable attention because of the analogy between the coordination chemistry of $\mathrm{Pd}(\mathrm{II})$ and $\mathrm{Pt}(\mathrm{II})$ complexes. In order to increase the kinetic stability of Pd(II) compounds, N,Schelating ligand have been successfully employed to enhance the activity of these species in the cellular medium. Thiosemicarbazide is a N,S-chelating ligands capable to coordinate via sulfur and nitrogen atoms, affording a stable five-memberedring. For this reason, this ligand would be of interest to prepare new biologically active Pd(II) complexes. Objectives: Thus, we presen here in the synthesis and cytotoxic evaluation against of the complexes of the type $[\mathrm{PdX}(\mathrm{tscz})$ $\left.\mathrm{PPh}_{3}\right] \mathrm{X}$, where tscz $=$ thiosemicarbazide, $\mathrm{PPh}_{3}=$ triphenylphosphine and $\mathrm{X}=\mathrm{Cl}(\mathbf{1})$ or $\mathrm{I}(\mathbf{2})$ Materials and Methods: Compound $\mathbf{1}$ was obtained from the reaction between $\left[\mathrm{PdCl}_{2}\left(\mathrm{CH}_{3} \mathrm{CN}\right)_{2}\right]$ and thiosemicarbazide (tscz), with further addition of triphenylphosphine. Complex 2 wa synthesized by substitution of the chlorido group by iodide. The compounds were characterized by elemental analysis, IR spectroscopy, and ${ }^{1} \mathrm{H}$ and ${ }^{5} \mathrm{C}$ NMR spectroscopy, differential therma analysis (DTA), and thermogravimetry (TG) and conductivity measurements. The cytotoxic activities of the complexes have been evaluated in vitro by MT assay against two cell lines: he cytotoxicity of cisplatin a standard metal-based antitumor drug was also evaluated under the the cyctions same condibe Restive. The cytoricity of 1 and 2 a $\mathrm{mL}$, respectively, being the value found for cisplatin $36 \mu \mathrm{g} / \mathrm{mL}$. With regard to $\mathrm{MCR}-5 \mathrm{cells}$, bo

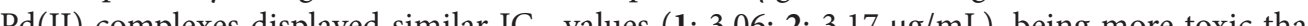

Financial support: We thank FAPESP, CNPq and the Institute of Chemistry.
Journal homepage: http: www.journalamb.com/index.php/jamb

Flow cytometry studies over NCI/ADR-RES tumor cells of a silver(i) complex with 5-fluorouracil: preliminary results

Julia Helena Bormio Nunes ${ }^{1 ;} ;$; Paula Pereira de Paiva ${ }^{2}$; Ana Lúcia Tasca Gois Ruiz ${ }^{2,3}$; João Ernesto de Carvalho ${ }^{2,3} ;$ Pedro Paulo Corbi ${ }^{1}$

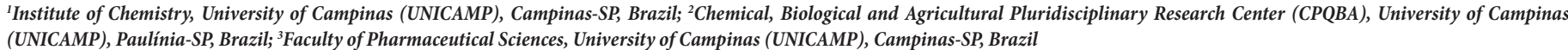
ARTICLE INFO

\section{Keywords:}

Flow Cytometry

Metal Complex

Anticancer Activity

ABSTRACT

(n) 5-fluorouracil (Ag-5fu) against multi-resistant ovarian tumor cells (NCI/ADR-RES) when compared to free 5-fluorouracil (5fu), silver nitrate $\left(\mathrm{AgNO}_{3}\right)$ and cisplatin. The enhanced activity of $\mathrm{Ag}$-5fu appeared to be a synergistic effect between $5 \mathrm{fu}$ and $\mathrm{AgNO}_{3}$, when comparing their iproliferative profiles. Objectives: Therefore, for a better understanding of the role of $5 f u$ and ilver(I) in the anticancer activity of Ag-5fu, we performed flow cytometry studies over NCI ADR-RES tumor cells, comparing the effects of Ag-5fu, $5 \mathrm{fu}$ and $\mathrm{AgNO}_{3}$ on cell cycle arrest and apoptosis induction. Materials and Methods: The multi-resistant human ovarian tumor cell Ine NCI/ADR-RES was obtained from the National Cancer Institute (Frederick-MA, USA). Stock cultures were grown in complete medium (RPMI 1640 supplemented with 5\% FBS and $1 \%$ penicillin/streptomycin) at $37^{\circ} \mathrm{C}$ with $5 \% \mathrm{CO}_{2}$. Solutions of the compounds $5 \mathrm{fu}$, Ag-5fu and $\mathrm{AgNO}_{3}$ were prepared in complete medium and difterent concentrations were used for the assays. For cell cycle arrest: $0.75 \mu \mathrm{g} \mathrm{mL}-1$ and $1.5 \mu \mathrm{g} \mathrm{mL}-1$ for $5 \mathrm{fu}$ and $\mathrm{AgNO}_{3}$, and $1.5 \mu \mathrm{g} \mathrm{mL}-1$ and $3.0 \mu \mathrm{g} \mathrm{mL}-1$ for Ag-5fu. For apoptosis induction (nexin): $1.5 \mu \mathrm{g} \mathrm{mL-1}$ for $5 f u$ and $\mathrm{AgNO}_{3}$, and $3.0 \mathrm{\mu g} \mathrm{mL}-1$ for Ag-5fu. The chosen concentrations were based on the metalligand proportion of the Ag-5fu complex (1:1 in mass). Cells were seeded in 6 and 12 well plates $\left(5 \times 10^{4}\right.$ cells $\left./ \mathrm{mL}\right)$ for cell cycle and nexin assays, respectively, for $24 \mathrm{~h}$ prior to treatment with the compounds.

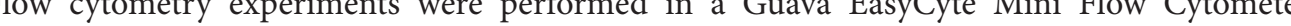
(Millipore, MA, USA) using Guava Cell Cycle and Nexin reagents (Merck Millipore) accordin to manufacturer's instructions. For all assays cells without treatment were used as negative controls. For cell cycle aryest cells were treated for 36 , while for hexh assay cells were treated for 18h. Results: Cell cycle assay showed the arrest in G1 phase by 5fu and Ag-5fu, but no for $\mathrm{AgNO}_{3}$, which did not arrest cell cycle in $36 \mathrm{~h}$. Nexin assay showed the induction of apoptosis for Ag-5fu and $\mathrm{AgNO}_{3}$, but not for $5 \mathrm{fu}$, which did not cause cell death for $18 \mathrm{~h}$ of treatment. The Agffu complex showed $11 \%$ cells marked only with annexin- $V$ and $49 \%$ cells double marked with annexin- $\mathrm{V}$ and $7-\mathrm{AAD}$, in contrast to $8 \%$ and $28 \%$ for $\mathrm{AgNO}_{3}$, , results show that in the Ag-5fu complex cell cycle arrest is caused by $5 \mathrm{fu}$, while cell death seem be triggered by apoptosis and caused by silver(I).

Financial support: CAPES, FAPESP (Grant \#2015/25114-4) and CNPq (\#442123/2014-0). 


\section{International Journal of Advances in Medical Biotechnology}

Journal homepage: http: www.journalamb.com/index.php/jamb

Complexes of V, Pt and Pd with amino acids and a-hydroxycarboxylic acids

Filipe Boccato Payolla ${ }^{1, *}$, Maurício Cavicchioli², Antonio Carlos Massabni ${ }^{1}$

\section{ARTICLE INFO}

\section{Keywords:}

Flow Cytometry

Metal Complex

Anticancer Activity

\section{ABSTRACT}

Introduction: Complexes of $\mathrm{Pt}(\mathrm{II}), \mathrm{Pd}(\mathrm{II})$ and $\mathrm{V}(\mathrm{IV}, \mathrm{V})$ show cytotoxic activity on tumor cells, but their low selectivity causes acute side effects. There are many works published in the literature that report that the structural modification of the complexes by using modified ligands is a effective method to enhance their activity as chemotherapeutic agents and decrease the side effects. Objectives: The main goals of the present work are the synthesis of new complexes of $\mathrm{V}$ Pt and Pd with amino acids, amino acid derivatives and $\alpha$-hydroxycarboxylic acids and to test the in-vitro cytotoxic activity. Materials and Methods: The amino acids and the $\alpha$-hydroxycarboxylic acids were used in their anion form. In general, the complexes were prepared in aqueous solution under reflux by using the molar proportion IM:IL and IM:2L. Complexes of $V$ with glutamic acid, lysine, 2,2-bypiridin, cysteine, gabapentin, phthalic, mesaconic and orotic acids were obtained and are being characterized. Complexes of Ptwith 5-FU (5-huouracil) and phthalic and mesaconic acids were obtained using the same procedure and were partially characterized. These complexes were tested with mouth and neck cancer cell lines. Complexes of Pt(II) and Pd(II) with gabapentin and orotic acid were obtained and are being tested for mutagenic and cytotoxic activity on diferent cell lines. Results. Preliminaty results show that the cytotoxic activity of the $\mathrm{Pt}-5$-FU complex is lower than cisplatin and higher than free 5-FU. Pt complexes with phthalic and mesaconic acids did not show any cytotoxic activity. This fact can be explained by the oxidation of P(II) to P(IV) dung the synthesis and a new synthetic method has been tested. Conclusions: Additional studies will be necessary to elucidate the structure of the complexes an

Financial support: To CAPES and FUNADESP for the fellowships.
International Journal of Advances in Medical Biotechnology

Journal homepage: http: www.journalamb.com/index.php/jamb

Study of the mutagenic potential of a new platinum complex by ames test

Rafaela Baldassari Silvestre ${ }^{1+*}$ Jaqueline Da Silva Colin'; Amanda De Lima Pizi Cândido'; Mariana Rodrigues Barreto'; Filipe Boccato Payolla ${ }^{1}$; Antônio Carlos Massabni'; Flávia Aparecida Resende

UNIARA - Universidade de Araraquara, Araraquara, Säo Paulo, Brazii

\section{ARTICLE INFO}

\section{Keywords:}

Metal Complex

Mutagenicity

Ames Test

ABSTRACT

Introduction: Over the years there has been a continuous interest in the chemistry of metal complexes, because of their key role in clinical therapy in biological applications of metal coordination compounds of biologically active ligands. Transition metals are particularly suitable for this purpose because they can adopt a wide variety of coordination numbers, geometries and oxidation states in comparison with other main group elements. However, one of the most important negative biological effects is the damage to DNA, since increases in DNA damage are associated with higher incidence of cancer and other different undesirable healt consequences, including infertility and genetic disorders. Objectives: Whereas, carcinogenicity and mutagenicity are among the toxicological effects that cause the highest concern for human health, the aim of his study was to investigate the mutagenic activity of the platinum complex with mesaconic acid (Pt-Mesac) by Ames test, a widely used assay that detects mutations at the gene level through strains genetically modified of the Samonella typhimurium bacteria. Material and Methods. Pt complex was produced and provided by the doctoral student Filipe Payolla ander the rest was performed using TA98, TA100, TA97a and TA102 strains of S. typhimurium, as sensitive indicators of DNA danage, in the absence (-SS) and presence ( concentrations, varying from 12.5 to $100 \mu \mathrm{g} /$ plate. Results: The results obtained showed that in the was not nugenic under the conditions used, because did not induce any increase the number of highly relevant. However, further pharmacological and toxicological investigations are necest is to determine the mechanism(s) of action to gual and their safer and more effective applicatio

Financial support: Funadesp and Fapesp (Brazil) 


\section{International Journal of Advances in Medical Biotechnology}

Journal homepage: http: www.journalamb.com/index.php/jamb

Synthesis, characterizationand antibacterial activities of a new $\mathrm{Au}$ (III) complex with hydrochlorothiazide Nayara A. S. Aquaroni ${ }^{1 *}$; Silmara C. Lazarini'; Douglas H. Nakahata²; Pedro P. Corbi²; Wilton R. Lustri ${ }^{1}$

University of Araraquarara - UNIARA, Araraquara, Säo Paulo, Brazail,? Inorganic Chemistry Department, Institute of Chemistry, University of Campinas - UNICAMP, Campinas-SP, Brazili,

\section{ARTICLE INFO}

\section{Keywords:}

$\mathrm{Au}(\mathrm{III})$

Antibacterial activities

BSTRACT

Introduction: The discovery of antibiotics can be considered one of the most significant achievements of modern science for the control of infectious diseases. However, the microbial resistance to antibiotics in use nowadays turns important the search for new compounds with better therapeutic efficiency and lower potential of development of bacterial resistance. One of the strategies to defeat the multiresistance is to combine metal ions, such as silver and gold with ligands that already possess biological activities and further evaluate their efficacies as novel antibacterial agents. Gold compounds, in special, have been considered as antibacterial agents since the discovery of the antimicrobial activities of potassium dicyanoaurate(I) by Robert Koch in the end of the $19^{\text {th }}$ century. Nowadays, gold compounds are mainly used as antiarthritic compounds, with emphasis to auranofin. Hydrochlorothiazide (HCZ), 6-chloro3,4-dihydro-2H-1,2,4-benzothiadiazine-7sulfonamide 1,1-dioxide, a thiazide diuretic, is often used in combination with other agents in the treatment of hypertension and patients with ischemic diseases. In the view point of coordination chemistry, HCZ can be considered versatile ligand, being able to coordinate to metal ions such as $\mathrm{Au}(\mathrm{I}, \mathrm{III})$. Objectives: Based on these considerations, a new $\mathrm{Au}$ (III) complex with HCZ, hereby identified as Au-HCZ, was prepared and evaluated about its antibacterial activities. Materials and Methods: The Au-HCZ complex was synthesized by the reaction of $\mathrm{HCZ}$ with $\mathrm{Li}[\mathrm{AuCl}]_{4}$ in an aqueous/alcoholic solution at $\mathrm{pH}$ 10. Elemental analysis indicated a 1:1 metal:ligand composition. Anal. calc. for $\mathrm{AuC}_{7} \mathrm{H}_{7} \mathrm{Cl}_{3} \mathrm{~N}_{3} \mathrm{O} \mathrm{S}_{2}$ (\%) C, 14.9; H, 1.25; N, 7.44. Found (\%) C, 14.4; H, 1.40; N, 6.80. The FTIR spectrum of the complex was evaluated in comparison to that of free HCZ. Changes in the absorption bands of the vibrational modes of the $\mathrm{N}-\mathrm{H}$ groups suggest nitrogen coordination to $\mathrm{Au}(\mathrm{III})$. Antimicrobial activity of Au-HCZ was preliminarily evaluated by disc diffusion and further confirmed by minimum inhibitory concentration (MIC) assays against bacterial strains Staphylococcus aureus ATCC25923, Escherichia coli ATCC25922 and Pseudomonas aeruginosa ATCC27853. Results: The MIC assay demonstrated the inhibitory activity of the complex against the considered strain with values of $2.13 \mathrm{mmol} \mathrm{L}^{-1}$ for $S$. aureus, $1.07 \mathrm{mmol} \mathrm{L}^{-1}$ for E. coli and $1.07 \mathrm{mmol} \mathrm{L}^{-1}$ for $P$. aeruginosa. Conclusions: Further studies are envisaged to confirm the potential of application of the Au-HCZ complex for treatment of bacterial infections.

Fnancial support: Brazilian agencies FAPESP (grant \# 2015/09833-0, 2015/25114-4), CAPES and CNPq (grant \# 442123/2014-0) and FUNADESP (National Foundation for the Development of Private Higher Education grant no. \# 2700316).

\section{International Journal of Advances in Medical Biotechnology}

Journal homepage: http: www.journalamb.com/index.php/jamb

Physical-chemical characterization and cellular viability study of baccharis dracunculifolia plant extracts

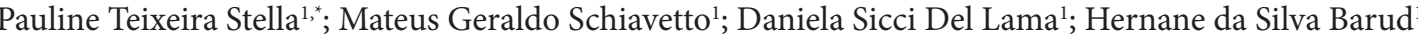

'Universidade de Araraquara - UNIARA

ARTICLE INFO

Keywords:

Vegetable extract

Baccharis dracunculifolia physicochemical characterization

ABSTRACT

Introduction and Objectives: Baccharis dracunculifolia (BD), also known as field rosemary occurs naturally in the South, Southeast and Center-West of Brazli, mainly in cerrado regions. Young BD leaves are formed by tectonic and glandular trichomes, and contain volatile and aromatic oils. Those oils give BD the typical aroma of the green propolis, produced by the insect Apis melifera. Divense therapeutic activites are available in the literature, and it is possible to highlight the anti-inflammatory, antioxidant, antimicrobial, immunomodulatory, cytotoxic hepatoprotective and antimutagenic activities. Development of new DB-based systems requires

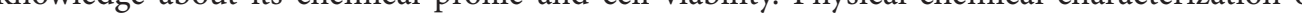
BD vegetal extracts (VE) and cell viability tests, through MTT assay, are the main focus of this work. Marerals and Methods. VE is provided by Ciclo Farma Indústria Química Eireli chemical industry, located in Serrana - SP - BR. Determination of flavonoids were performed by UV/VIs spectroscopy, and the same extracts have also been subjected to fibroblast cell viability assays. Results and Conclusions: Up to the present moment, the presence of phenolic compounds and

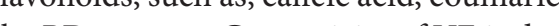
he $\mathrm{BD}$ extracts. Cytotoxicity of $\mathrm{VE}$ is dose-dependent, and can be tuned by $\mathrm{BD}$ concentration.

Financial support: Fapesp 


\section{International Journal of Advances in Medical Biotechnology}

Journal homepage: http: www.journalamb.com/index.php/jamb

Search for high-added value compounds from soya crops agricultural waste

Ariadne Magalhães Carneiro ${ }^{1 ;} ;$ Maiara Borges ${ }^{1} ;$ Daniel Rinaldo ${ }^{1} ;$ Cristiano Soleo Funari

\section{ARTICLE INFO}

\section{Keywords:}

Isoflavones

Agricultural waste

BSTRACT

Introduction: It is estimated that a quarter of the approximately 140 billion tons of agricultural biomass produced per year worldwide is produced in Brazil, and that more than $30 \%$ of the total waste produced in this country are agricultural wastes. According to the United Nations, there is the need to intensify research on technologies for converting agricultural waste into useful resources to society. Furthermore, the search for compounds of interest in waste by means of dvanced value-added strategies based on green technologies, before adding them to low valueadded products, has been seen as a business opportunity. Soya crops corresponds to almost $60 \%$ of total cultivated are in Brazil having a strong impact in Brazilian GDP, but also in the generation of agricultural waste in Brazil. Soybeans are known to be one of the main sources of isoflavones, class of flavonoids with innumerable properties for human health. Isoflavones rich extracts of soy beans are largely commercialized for the treatment of women who are going through climacteric Objectives: This work aimed to investigate the potential of soya agricultural wastes (stems, leaves and twigs of soybeans) as raw materials for the preparation of phenolic rich extracts based on green solvents. Materials and Methods: Samples were extracted by dynamic maceration and nalysed by HPL-DAD/UV. Results: Overall, the greener ethanol and acetone provided better extractions than those observed for the reference solvent acetonitrile, an undesired chemical from the sustainability point of view. Isoflavones were found in stems and leaves together with other flavonoids, whereas the twigs showed to be a rich source of flavones. Conclusions: These residues showed potential to be raw materials for the production of flavonoid rich extracts rathe than simply waste. The green solvents ethanol and acetone were able to replace acetonitrile for such extractions.

Financial support. Săo Paulo Research Foundation (FAPESP) and the Conselho Nacional de De. \#45398 2014-5)

\section{International Journal of Advances in Medical Biotechnology}

Journal homepage: http: www.journalamb.com/index.php/jamb

Curcumin-cinnamaldehyde hybrids against Xanthomonas citri subsp. citri

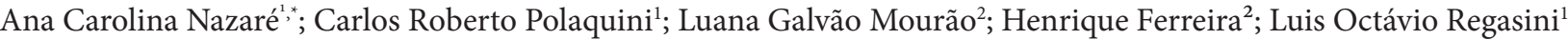

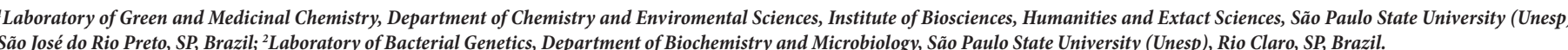
ARTICLE INFO

Keywords:

Xanthomonas citri subsp. citri

Curcumin

Cinnamaldehyde

\section{ABSTRACT}

Introduction: Citrus canker is one of the most aggressive citrus diseases, affecting the cultivation of citrus plants in some tropical areas. This disease is caused by Xanthomonas citri subsp. citri (Xac) and occurs in major orange juice producing countries, including Brazll and the USA. Chemical control of this disease has become ineffective, due to irrational use of cupric compounds. Recently, it was identified copper-resistant genes in Xac, which difficulted its eradication. Nevertheless, efforts are needed to identify and develop innovative anti-Xac compounds. Molecular hybridization is a widely used medicinal chemistry tool for design of bioactive compounds, we purposed hybridization using curcumin and cinnamaldehyde. Curcumin and Cinnamaldehyde are natura products used in cooking and medicine that exhibit broad spectrum antibacterial action against Gram-positive and Gram-negative species. Objectives: The objective of this work was to evaluate anti-Xac activity of curcumin-Cinnamaldehyde hybrids (CCH). Materials and Methods: Firstly, a series of $\mathrm{CCH}$ (1-12) was synthesized and their structures were confirmed by $1 \mathrm{H}$ and $13 \mathrm{C}$ NMR. The minimum inhibitory concentration (MIC) of compounds against Xac was performed by the Resazurina Microtiter Assay. Results: Among evaluated compounds, 12 showed greater potency, with MIC value of $42.94 \mu \mathrm{g} \mathrm{mL}-1$. Its minimum bacterial concentration (MBC) was determined at $100 \mathrm{gg} \mathrm{mL}-1$ and compound 12 inhibit Xac growth. Thus, 12 was selected for Xac cell treatment evaluation by measuring the cell multiplication capacity in artificially inoculated "Plant tissues through the pathogenicity assay. In planta assay was performed on sweet orange "Pera Rio" (Citrus sinensis). Seedling were contaninated by Xac and subsequently treated by 12 at concents performed with 12 inhibited the Xac growth in both concentrations. Conclusions. In conclusion, cy mor not able to demonstrate significant bacterial death.

Financial support: Coordination for the Improvement of Higher Education Personnel (CAPES), Brazilian Council for Scientific and Technological Development (CNPq) and the Sao Paulo Research Foundation (FAPESP). 


\section{International Journal of Advances in Medical Biotechnology}

Journal homepage: http: www.journalamb.com/index.php/jamb

Bioinspired surgical clip and coated with natural drugs from the Amazon

Thays Obando Brito ${ }^{1+}$; Renata Nunes Oliveira ${ }^{2}$, Leonardo Sales Araujo ${ }^{1}$ L Luiz Henrique de Almeida

'Federal University of Rio de laneiro - UFR]'; 'Federal Rural University of Rio de Janeiro - UFRR/

\section{ARTICLE INFO}

Keywords:

Surgical clip

Coating

Drugs from Amazon

ABSTRACT

Introduction: The suture is the closing of edges of a wound to approach tissues and to seal blood vessels. The use of ant mandible to suture wounds has been reported approximately 1,000 years BC, quoted in the Indian medical text Charaka Samhita. The specie used in this process was the Atta laevigata ant, because it has adequate size for manipulation, design and its biomechanics are perfect for opening and closing the mandible and to approach the edges of the wound. In addition, the species releases through the mandible a substance that works as an antibacterial agent for the injury, making this natural system self-sufficient in the suture. Based on this knowledge, it was developed the surgical clip bioinspired (MU9102934-1). The new mechanic system facilitates the handling both in its placement of the clip and also in its removal from the skin, which is less traumatic and efficient for the patient than the traditional clamping devices. The surgical clip will be coated with Carapa guianensis oil, popularly known as Andiroba an Pterodon emarginatus oil, popularly known as Sucupira. These oils are extracted from medicina plants of the Amazon and they are traditionally used by Riverine peoples. The natural oils present efficient analgesic, anti-bacterial, anti-inflammatory, anti-fungal and anti-allergic properties an they were also found to be effective in the healing process. Objectives: The objective of this work is to coat the surgical clip with natural antibacterial oils improve its performance in the healing process. Materials and Methods: In this work, the coatings using the solution composed by natural oils and acetone were dip coated on the surface of the material AISI 420 after differen intervals of time of immersion and drying. In addition, the natural oils characterization was carried out using the Fourier Transform Infrared Spectroscopy-FTIR. The adhesion of the oils to the clip surface was evaluated by morphological analysis: Electron Microscope Scanning - SEM and Microscope of Atomic Strength - AFM, including the verification of the in vitro cytotoxicity potential of the surgical clip coated with drugs. Results: The adherence results of the solution on the AISI 420 samples surface were similar after $30 \mathrm{~s}$, I min and $1.5 \mathrm{~min}$ of immersion, as well as after $2 \mathrm{~min}, 4 \mathrm{~min}$ and $6 \mathrm{~min}$ of drying, respectively. In addition, the coated samples proved to be effective on bioassays conducted with bacteria and fungi. Conclusions. The results support the traditional use of natural oils as antibacterial agents. They can be considered promising coating on the bioinspired surgical clip.

Financial support: Foundation of Research Support of the Amazonas State - FAPEAM
International Journal of Advances in Medical Biotechnology

Journal homepage: http: www.journalamb.com/index.php/jamb

Study on the mutagenic potential of kaurenoic acid, a bioactive diterpenoid present in Copaiba oil, by Ames test

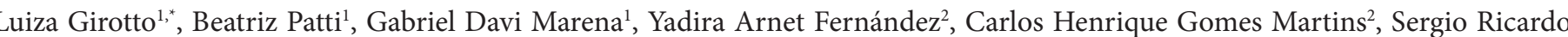
Ambrósio ${ }^{2}$ Jairo Kenupp Bastos ${ }^{3}$ Flávia Aparecida Resende

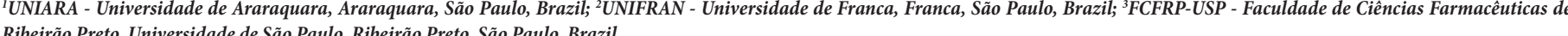
ARTICLE INFO

\section{Keywords:}

kaurenoic acid

Mutagenicity

BSTRACT

Introduction: Plants that belong to Copaifera spp. are rich in kaurenoic acid, a diterpene that showed a wide variety of interesting biological activities, including antiparasitic and antimicrobial effects, anti-inflammatory action, and cytotoxicity against human cancer cells and hemolytic effects against mouse erythrocytes. However, previous studies showed that exposure of V79 cells to higher concentrations of kaurenoic acid caused significant increases in cell damage index and frequency. Objectives: To complement the results of the literature, their mutagenic activity was assessed by Ames test in this study. This assay detects mutations at the gene level through strains genetically modified of the Samonella typhimurium bacteria. Materials and Methods In this study, it was performed using TA98, TA100, TA97 and TA102 strains of S. typhimurium in the absence (-S9) and presence ( + S9) of metabolic activation system, in five concentrations varying from 25 to $200 \mu \mathrm{g} /$ plate, established in previous cytotoxicity studies. Results: The result obtained showed that kaurenoic acid was not mutagenic under the conditions used, because did not induce any increase in the number of revertant colonies relative to the negative control. Conclusions: The absence of mutagenic effect against $S$. typhimurium bacterial strains in the Ames test is highly relevant. However, in light of the above and of the findings of the literature it is necessary to clarify the conditions and the mechanisms that mediate the biological effects of kaurenoic acid before treating it as therapeutical agent, because the balance between the therapeutic vs. the toxicological effects is an important parameter in assessing its applicability in relation to phytotherapeutic potential.

Financial Support: UNIARA and FAPESP 


\section{International Journal of Advances in Medical Biotechnology}

Journal homepage: http: www.journalamb.com/index.php/jamb

Evaluation of the Cytotoxic activity of standardized extracts of myrcia bella cambess. (Myrtaceae)

Gabriel Davi Marena ${ }^{1, *}$; Nathalia Ferreira Fregonezi1'; Mariana Rodrigues Barreto ${ }^{1}$; Luiz Leonardo Saldanha ${ }^{2}$; Anne Lígia Dokkeda Bosqueiro²; Flávia Aparecida Resende ${ }^{1}$

'UNIARA - Universidade de Araraquarara, Araraquara, Säo Paulo, Brazili' 'UNESP-Instituto de Biocièncias de Botucatu, Botucatu, Säo Paulo, Brazili.

ARTICLE INFO

\section{Keywords:}

Myrcia bella

Cytotoxicity

MTT assay

\section{ABSTRACT}

Introduction: Plant-based systems continue to play an essential role in healthcare, and their use by different cultures has been extensively documented. Moreover, medicinal plants have historically proven their value as a source of molecules with therapeutic potential, and nowadays still represent an important pool for the identification of novel drug leads. Myrcia bella, common and inportant species in many savanna fragnents, distributed in the state of Sao Paulo, has potential use in the traditional medicine for treatment of diabetes mellitus. However, little obown about their undesirable properties such as mutagenicity, carcinogenicity and toxicity. Objectives: Thus, the aim of this study was to investigate the cytotoxicity of standardize extracts ( $70 \%$ ethanol) of leaves of M. bella. Materials and Methods: Cytotoxicity was assessed by changes related to metabolic functions of mitochondria detected by a colorimetric method known as MTT (tetrazolium 3-(4,5-dimethylthiazol-2-yl)-2,5-diphenyl tetrazolium bromide) in a normal cell line (GM-07492 - human lung fibroblasts) and a cell line with metabolism profile of carcinogens (Hep G2 - human hepatocellular carcinoma). Results: According to the results, $M$ bella induced a statistically significant reduction on cell viability of the HepG2, in all concentration tested compared to the negative control. In the treatments with the GM-07492 cultures, M. bell revealed lack of cytotoxicity; cell viability of the extract was greater than $80 \%$ Conclusions: The festure cling in Eture clinical researches. However, further toxicological tests are needed to ensure its sofe use.

Financial support: Uniara and Fapesp (Brazil)

Journal homepage: http: www.journalamb.com/index.php/jamb

Toxicity evaluation of cinnamylideneacetophenones against human cervical cancer cells positive for HPV16 and HPV18

Daiane Bertholin Anselmo ${ }^{1, *}$; Carlos Roberto Polaquini'; Guilherme da Silva Torrezan ${ }^{1}$; Paula Rahal'; Marília de Freitas Calmon ${ }^{1 ;}$ Luis Octávio Regasini

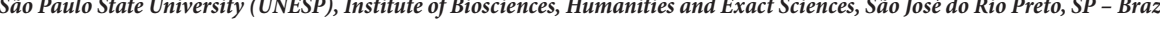

\section{ARTICLE INFO}

\section{Keywords:}

Cinnamaldehyde

Antitumorals

Cervical Cance

ABSTRACT

Introduction: Human Papilloma Virus (HPV) is the main causative agent of cervical cance including HPV 16 and HPV 18 types, which have been found in $99 \%$ of cases. In worldwide, cervical cancer is the most common cause of cancer related deaths anng wom. In. In Brazil, cervical cancer is the third most frequent tumor, with 5.430 cases of deaths reported by INCA. It was estimated 16.340 new cases reported in 2016. Thus, there is a need for innovative compound against cervical cancer. In this context, screening of natural compounds constitutes an valuable alternative for the discovery of antineoplastic agents. Cinnamaldehyde is the main chemical constituent of essential oil from Cinnamomum cassia. This compound has demonstrated to be an cytotoxic agent against several human cancer cells. Objectives: Thus, the objective of this work was to evaluate toxicity of named as cinnamylideneacetophenones (cinnamaldehyde derivatives) against human cenvical carcinoma cells positive for HPV16 (CaSki ATCC CRM-CRL-1550) and HPV (HeLa ACC CCL-2). Materials and Methods: Cells were treated with substances 1 4 and cinnamaldehyde, which was used as a positive control, in concentrations ranging from 0.75 to $800 \mu \mathrm{mol} L$ to derive $\mathrm{IC}_{50}$ (concentration capable of inhibiting $50 \%$ of the cells). Cellular viability was evaluated after $48 \mathrm{~h}$ by MTT assay. This methodology evaluates cell metabolic activity, measuring on spectrophotometer the reduction tetrazolium bromide in formazan by cerivity of mitochondrial dehydrogenases. The experiments were performed in triplicate and in 列 post hoc test using Graph-Pad Prism 7.0 software. Results: Out of 4 compounds, 2 showed the f $37.78 \pm 8.20$ and $59.13 \pm 2.41$ a $4 \mathrm{~L}^{-1}$ respectively $(\mathrm{p}<0.01$ s. col (t) is sugested cinnamylideneacetophen ( 4 an 4 w 2 and 4 were more potent than cinnamaldehyde. The presence of hydroxyl group at 3 position cytority, when compared to cinnaldehy. These compounds are hits for developerior

Financial support: Capes, Fapesp, CNPq, PROPg-Unesp, PROPe-Unesp 
Synthesis, antibacterial and antitubercular activities of cinnamaldehyde derivatives

Carlos R. Polaquini1 ${ }^{1 *}$; Guilherme S. Torrezan ${ }^{1}$; Vanessa R. Santos ${ }^{2}$; Ana C. Nazaré'; Débora L. Campos ${ }^{3}$; Laíza A. Almeida ${ }^{1}$; Fernando R. Pavan'; Cristiane Duque'; Luis O. Regasin

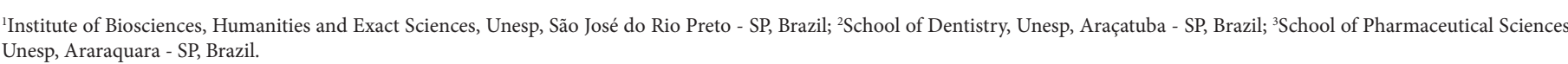

ARTICLE INFO

\section{Keywords:}

Cinnamaldehyde

Antimicrobial

Antibacterial

BSTRACT

Introduction: Cinnamaldehyde (CMD) is the majority component in cinnamon bark oil, and it is responsible for its spicy and sweet. The spectrum of antibacterial activity of CMD has been extensively reported and includes effects against Gram-positive, Gram-negative and mycobacteria species. The mode of action of CMD involves bacterial multi-targets, including membrane disruption, cell division inhibition, and reactive-oxygen species induction. CMD possess aliphatic aldoxyl group, which is an undesirable functionality due to its high reactivity. Objectives: Herein, we designed and synthesized a series of derivatives with the replacement of aldoxyl group by acetophenone moiety. Materials and Methods: Their antibacterial an antitubercular activities were evaluated against Gram-positive and Gram-negative species, as well as Mycobacaterium tuberculosis. In addition, hydrophilicity of all compounds was measured by HPLC-PAD experiments, which enabled calculation of partition coefficients $(\log P \mathrm{O} / \mathrm{w})$ Synthesis of derivatives was achieved by aldol condensation between CMD and corresponding acetophenone under basic catalysis, at room temperature. For antibacterial and antitubercular evaluations were used Staphylococcus aureus ATCC 14458 (Sa), Streptococcus mutans ATCC 25175 (Sm), Streptococcus sanguinis ATCC 10557 (Ss), Pseudomonas aeruginosa ATCC 15442 (Pa), Escherichia coli ATCC 10536 (Ec), and M. tuberculosis ATCC $27294(M t)$. MIC and MBC were determined by broth microdilution method, in 96 -well microtiter plates. We calculated the $\log$ Po/w by using HPLC-PAD method suggested by OECD protocols. Results: Phenolic derivatives 2 and 3 exhibited MIC and MBC values of 19.5 to $78.1 \mu \mathrm{g} / \mathrm{mL}$ against $S a$, Sm, and Ss. Also, amino- (4) and vanillyl- (7) derivatives exhibited activity against $S m$ and $S a$ (MIC = $\mathrm{MBC}=78.1 \mu \mathrm{g} / \mathrm{mL}$ ). Derivatives bearing hydrophobic and electron-with drawing substituents were inactive against $S a, S m$ and $S s$. These results indicate electron-donating and hydrophilic groups enhanced antibacterial activity. Bioactive derivatives against Gram-positive species were not able to inhibit Gram-negative species growth. Compounds 1, 6, 9, and $\mathbf{1 7}$ presented potent effects against $M t(13.2 \mu \mathrm{g} / \mathrm{mL} \leq \mathrm{MIC} \leq 23.4 \mu \mathrm{g} / \mathrm{mL})$. The electronic nature of substituent was not relevant for antitubercular activity. Anti-Staphylococcus and anti-Streptococcus compound exhibited $\log P_{0} / \mathrm{w}$ values ranging from 2.5 to 3.3. Among these, $\mathbf{2}$ and $\mathbf{3}$ were the most potent, with $\log P \mathrm{o} / \mathrm{w}$ values of 2.7 and 2.6, respectively. The four most active anti-Mycobacterium compounds presented $\log P \mathrm{Po} / \mathrm{w}$ values ranging from 3.2 to 3.5 . Highly hydrophobic compound displayed $\log \mathrm{Po} / \mathrm{w}>3.5$ and were not able to act against Sa, Sm, Ss, and Mt. Preliminary structure-activity relationship (SAR) investigations suggested hydrophilicity is central parameter for antibacterial and antitubercular activities of CMD derivatives. Conclusions: Furthermore, our results corroborated the potential of $\mathrm{CMD}$ as privileged starting material and template for synthetic collection of hits.

Financial support: CAPES, CNPq and FAPESP
Journal homepage: http: www.journalamb.com/index.php/jamb

Antimycobacterial activity of dehydrozingerone derivatives

Gabriela Miranda Ayusso ${ }^{1, *} ;$ Mariana Bastos dos Santos ${ }^{1}$; Débora Leite Campos²; Fernando Rogério Pavan²; Luis Octavio Regasini ${ }^{1}$ Institute of Biossience,
(UNESP - Araraunara)

ARTICLE INFO

Keywords:

Tuberculosis

Mycobacterium tuberculosis

Dehydrozingerone

Derivatives, antinycobacteria

Tuberculostatic

Hydrophobic

ABSTRACT

Introduction: Tuberculosis, an infectious disease of worldwide distribution, is considered serious public health problem. The causative agent of tuberculosis is Mycobacterium tuberculosis, an aerobic bacterium, which has not capsule and spores. Emergence of resistant strains of $M$. tuberculosis, HIV co-infection and existence of latent intramacrophagic bacilli led to the search for innovative drugs, allowing greater adherence of the patient to treatment. Dehydrozingerone (DZG) is a phenolic compound from ginger rhizomes (Zingiber officinale). DZG has demonstrate several biological activities, such as: cardiovascular protection, anti-inflammatory, antitumoral antimutagenic, antioxidant, antidepressive, anti-Alzheimer, antimalarial, antifungal, antibacteria and hypoglycemic. Objectives: This study aimed to synthesize and evaluate tuberculostatic activity of 10 DZG derivatives against M. tuberculosis. Materials and Methods: DZG derivative were synthesized by aldol condensation reactions between DZG and benzaldehyde derivatives substituted by electron acceptor and donor groups, as well as hydrophilic and hydrophobic groups. For synthesis of DZG, it was used aldol condensation reaction between vanillin and acetone. DZG dervatues were evaluated in witro against $M$. tuberculosis H37Rv strain (ATCC 27294) by broth dilution method coupled with the Resazurin Microtiter Assay (REMA). Compound were tested in concentrations ranging from 25.0 to $0.09 \mathrm{gg} \mathrm{mL}^{-1}$ for determination of minimum (nibitory concentration capable of inhiting was used as reference tuberculostatic. Results. Derivatives $2,3,5,7,9$ and 10 demonstrated antimycobacterial activity with $\mathrm{MIC}_{90}$ values ranging from 8.0 to $2.4 \mu \mathrm{g} \mathrm{mL}$. In general, it was observed that presence of para-substiturions on $\mathrm{ning}$ B by hydrophobic groups enhanced antivity In addition, it was evident that the cyclization, which prom ctrity. In an triggered a decrease restriction, triggered a decrease toward antimycobacterial activity. Therefore, structure-activity therculost tic ativity Concluin of natural products for the design of innovative tuberculostatic agents.

Financial support: FAPESP, CAPES, CNPq, PROPe - UNESP, PROPG - UNESP 


\section{International Journal of Advances in Medical Biotechnology}

Journal homepage: http: www.journalamb.com/index.php/jamb

Synthesis and anti-staphylococcus aureus activity of aminochalcones

Mayara Aparecida Rocha Garcia ${ }^{1} * ;$ Janaína de Cássia Orlandi Sardi²; Luís Octavio Regasini ${ }^{1}$

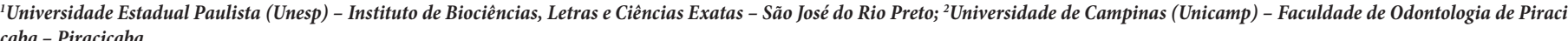
ARTICLE INFO

\section{Keywords:}

Antimicrobial

Aminochalcones

Antibacterial

Staphylococcus Aureus

ABSTRACT

Introduction: Bacterial resistance is a natural phenomenon, which has been enhanced after use of antibiotics, generating superbugs, which are resistant to several drugs. The indiscriminate use of antibiotics, slow rate diagnoses and poor hospital hygiene are factors of bacterial resistance. Thus the discovery of innovative antibacterial agents is necessary. Chalcones are privileged scaffolds in Medicinal Chemistry, which have exhibited broad spectrum of pharmacological activities, such as antibacterial, antifungal, antimalarial, antiviral, antioxidant and anti-inflammatory. Objectives The objective of this work wasto synthesis and evaluation of $2^{2}-3^{2}$ - and 4 -aminochalcones again Staphylococcus aureus. Materials and Methods: A series of aminochalcones was synthesized by benzaldehyde derivatives. Their antibacterial activity was tested against methicillinoureus ATCC 25923 (MSSA) and methicillin-resistant S. oureus ATCC 33591 (MRSA). Bactive susceptibility activity was expressed as values of Minimum Inhibitory Concentation (MIC) and Minimum Bactericidal Concentration (MBC). Chalcones were tested in concention ranging from 0.48 to $62.5 \mathrm{~kg} \mathrm{~mL}^{-1}$. Vancomycin was used as reference antibiotic. Resuls

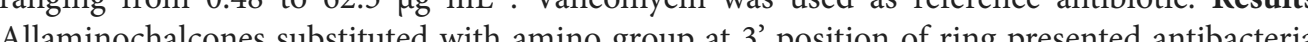
ctivity. Amo these, aninoclat

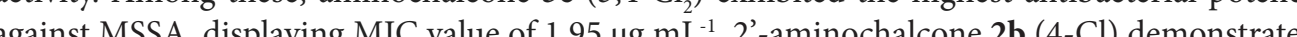
the highest anti-MRSA potency demonstrating MIC value of $7.8 \mathrm{~m} \mathrm{~mL}^{-1} .4^{\prime}$-aminochalcones were not able to inhibit MSSA and MRSA growth. Aminochalcone 3 e was twice less potent the vancomycin dipping MIC value of $1.95 \mathrm{Hg} \mathrm{mL}^{-1}$ against MSSA. For the times less active against MRSA (MIC $=7.8 \mathrm{M} \mathrm{mL}^{-1}$ ). Conclusions: These results sugested

Financial support: Capes, CNPq and Fapesp

Synthesis and trichomonicidal activity of hydroxychalcones

Thaíse Carla Borges ${ }^{1 \text {; }}$, Lígia Rodrigues e Oliveira ${ }^{1}$; Márcia Rodrigues Trein ${ }^{2}$, Tiana Tasca ${ }^{2}$; Luis Octavio Regasini ${ }^{1}$.

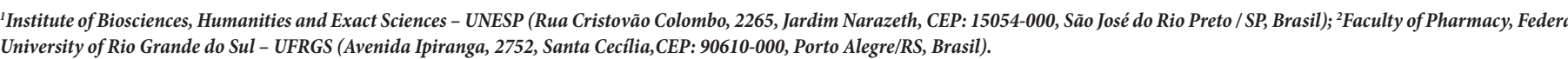
ARTICLE INFO

Keywords:

Trichomonas

Trichomoniasis

Hydroxychalcones

ABSTRACT

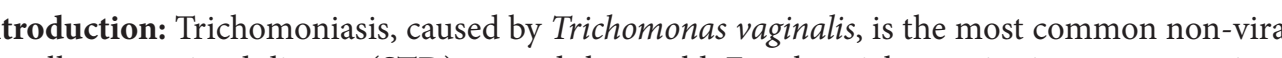
sexually transmitted disease (STD) around the world. For the trichomonias is treatment, nitrocompounds, metronidazole and secnidazole are the most prescribed, although there are severa resistant strains and severe adverse effects. Thus, the search for new trichomonicidal agents is af hent. Objectives. Th the present work, hydroxychalcones were designed, evaluating importance the Cof condensation reaction of Claisen-Schidt. The stictures of substances were confirmed by a 3 in ghint sting 50\% growth (IC). These substes were submitted to toxicity tests an capale of

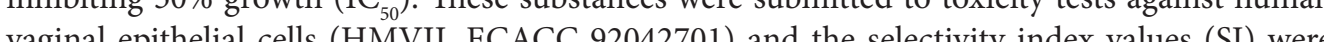
established by the ratio of the letal Chalcones with hydroxyl on ring A exhibited ctivity 0 ainst $T$ vaginalis higher the hydroxyl on ring $B$, being the first used for bioactivity optimization steps. Among these, the

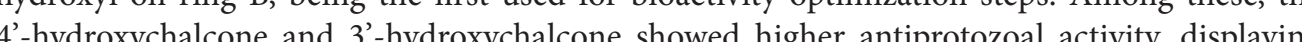
IC values of 27.5 and 49.4 M respectively On the other hand, 2'-hydroxychaty, displaying $\mathrm{IC}^{50}$ of $76.4 \mu \mathrm{M}$. However hydroxychacones did not show selectivity and were toxic to host cells, with SI of values ranging 0.5 to 1.1 . Conclusions: The hydroxyl group at $3^{\prime}$ and 4' position were crucial for trichomicidal activity. With draw and donting groups donors maintained decreased potency for the $3^{\prime}$ - hydroxychalcone and 4'-hydroxychalcone frameworks.

Financial support: CNPq, CAPES, FAPESP, PROPe-UNESP, PROPG-UNESP 


\section{International Journal of Advances in Medical Biotechnology}

Journal homepage: http: www.journalamb.com/index.php/jamb

In vitro bacterial reverse mutation assay: mutagenicity study of oleoresin of copaifera langsdorffii

Giovanna Fortunato ${ }^{1, *}$, Luiza Girotto ${ }^{1}$, Beatriz Patti Rocha' ${ }^{1}$, Yadira Arnet Fernández ${ }^{2}$, Carlos Henrique Gomes Martins ${ }^{2}$, Sergio Ricardo Ambrósio², Jairo Kenupp Bastos ${ }^{3}$, Flávia Aparecida Resende'

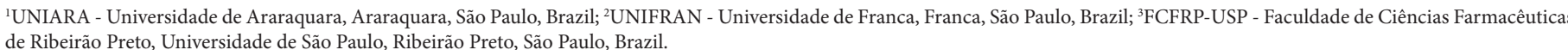
ARTICLE INFO

\section{Keywords:}

Copaifera langsdorfii

Mutagenicity

BSTRACT

Introduction: In recent times, many studies have been directed towards the identification of natural products with therapeutic properties, given the increased use of plant products for cultural, medicinal and social purposes. These natural products can be used directly or may be extracted to identify new bioactive compounds. So, it is essential to evaluate their biological effects to minimise the potential risks to human health. In this context, studies concerning genotoxicity may indicate the safety and effectiveness of herbal health products. Objectives: Thus, the aim Copaifera langsdorffii by the the mutagenic activity of oleoresin extracted from the trunk was performed using TA98, TA100, TA97 and TA102 strains of Salmonella typhimurium in the absence $(-S 9)$ and presence $(+S 9)$ of metabolic activation system, in five concentrations, varying from 0.5 to $4.0 \mathrm{mg} /$ plate. Results: The results obtained showed that $C$. langsdorffii oleoresin did not induce any increase in the number of revertant colonies relative to the negative control, indicating the absence of mutagenic activity. Conclusions: The absence of mutagenic effect by this oleoresin against S. typhimurium bacterial strains in the Ames test is highly relevant, and is a positive step towards ensuring its safe use in medicine. However, further pharmacological and toxicological investigations are necessary to determine the mechanism(s) of action to guarante their safer and more effective application to human health.

Financial support: Uniara and Fapesp (Brazil)
International Journal of Advances in Medical Biotechnology

Journal homepage: http: www.journalamb.com/index.php/jamb

In vitro mutagenicity of murraya paniculata assayed by bacterial reverse mutation (Ames) test

aqueline da Silva Colinn ${ }^{1 ;}$; Rafaela Baldassari Silvestre'; Amanda De Lima Pizi Cândido'; Mariana Rodrigues Barreto'; Celia Magaly Casado Martin²; André Gonzaga²; Flávia Aparecida Resende'

'UNIARA - Universidade de Araraquara, Araraquara, Säo Paulo, Brazail'?2'UNESP - Faculty of Pharmaceutical Sciences of Araraquara, Araraquara, Säo Paulo, Brazit

\section{ARTICLE INFO}

Keywords:

Medicinal plants

Ames test

Mutagenicity

Antroduction: The use of medicinal plants as alternative remedies has been increasing over ime. The species of the genus Murraya has been traditionally used as an analgesic and local anesthetic for the treatment of eczema and rheunatism. Murraya paniculata, belonging to the Rutaceae family, has a great diversity of secondary metabolites. So, it has aroused interests in the research on its chemical, biological, chemosystematic and pharmacological aspects. However, despite being a natural extract and known by its popular use, little is known about its mutagenic potential. It is essential the evaluation the mutagenicity of extracts used by the population with therapeutic efficacy, since the cancer and other pathologies can come from mutations in the DNA. Objectives. 1hus, the alm of the present study was to determine the mutagenic effects of the ethanolic extract of the leaves M. paniculata by the Ames test. Materials and Methods: The extract was produced and provided by the doctoral student Celia Magaly Casado Martin in the Laboratory or Pharmacognosy of the Faculty of Pharmaceutical Sciences of Araraquar (UNESP), under the responsibility of Prof. Dr. Andre Gonzaga. The Ames test uses bacteria as sensitive indicators of DNA damage, and a rat liver homogenate ( 59 microsomal fraction) for metabolic conversion of carcinogens to their active mutagenic forms. In this study, the Ames test was performed using the preincubation methodology with TA98, TA100, TA97 and TA102 strains of Salmonella typhimurium in the absence (-S9) and presence (+S9) of metabolic

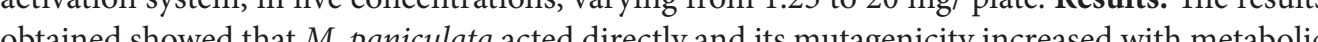
bed son (TA100). According to the strains inved, (TAr), and, at a mech higher rate, frameshift mutations (TAg8 and TAYa). Conclusions: Considening that he extract is a conplex nixt Cract

Financial support: Uniara and Fapesp (Brazil) 